OPEN ACCESS

Edited by:

David W. Graham,

Newcastle University, UK

Reviewed by:

Claudio Palmieri,

Marche Polytechnic University, Italy

Marco Fondi,

University of Florence, Italy

*Correspondence:

Marco R. Oggioni

mro5@/eicester.ac.uk

Specialty section:

This article was submitted to Antimicrobials, Resistance and

Chemotherapy,

a section of the journal

Frontiers in Microbiology

Received: 27 February 2016

Accepted: 13 June 2016

Published: 28 June 2016

Citation:

Furi L, Haigh R, Al Jabri ZJH,

Morrissey I, OU H-Y,

León-Sampedro R, Martinez JL,

Coque TM and Oggioni MR (2016)

Dissemination of Novel Antimicrobial Resistance Mechanisms through the Insertion Sequence Mediated Spread of Metabolic Genes.

Front. Microbiol. 7:1008. doi: 10.3389/fmich.2016.01008

\section{Dissemination of Novel Antimicrobial Resistance Mechanisms through the Insertion Sequence Mediated Spread of Metabolic Genes}

\author{
Leonardo Furi ${ }^{1,2}$, Richard Haigh ${ }^{1}$, Zaaima J. H. Al Jabri ${ }^{1}$, lan Morrissey ${ }^{3}$, Hong-Yu Ou ${ }^{4}$, \\ Ricardo León-Sampedro ${ }^{5,6}$, Jose L. Martinez ${ }^{7,8}$, Teresa M. Coque ${ }^{5,6,8}$ and \\ Marco R. Oggioni ${ }^{1,2 *}$ \\ ${ }^{1}$ Department of Genetics, University of Leicester, Leicester, UK, ${ }^{2}$ Dipartimento di Biotecnologie Mediche, Universita di Siena \\ Siena, Italy, ${ }^{3}$ IHMA Europe Sàrl, Epalinges, Switzerland, ${ }^{4}$ State Key Laboratory for Microbial Metabolism and School of Life \\ Sciences and Biotechnology, Shanghai Jiaotong University, Shanghai, China, ${ }^{5}$ Departamento de Microbiología, Instituto \\ Ramón y Cajal de Investigación Sanitaria, Hospital Universitario Ramón y Cajal, Madrid, Spain, ${ }^{6}$ Centro de Investigación \\ Biomédica en Red de Epidemiología y Salud Pública (CIBERESP), Spain, ${ }^{7}$ Departamento de Biotecnología Microbiana, \\ Centro Nacional de Biotecnología, Consejo Superior de Investigaciones Científicas, Madrid, Spain, ${ }^{\circ}$ Unidad de Resistencia a \\ Antibióticos y Virulencia Bacteriana (RYC-Consejo Superior de Investigaciones Científicas), Madrid, Spain
}

The widely used biocide triclosan selectively targets Fabl, the $\mathrm{NADH}$-dependent trans-2-enoyl-acyl carrier protein (ACP) reductase, which is also an important target for the development of narrow spectrum antibiotics. The analysis of triclosan resistant Staphylococcus aureus isolates had previously shown that in about half of the strains, the mechanism of triclosan resistance consists on the heterologous duplication of the triclosan target gene due to the acquisition of an additional fabl allele derived from Staphylococcus haemolyticus (sh-fab/). In the current work, the genomic sequencing of 10 of these strains allowed the characterization of two novel composite transposons TnSha1 and TnSha2 involved in the spread of sh-fabl. TnSha1 harbors one copy of IS1272, whereas TnSha2 is a $11.7 \mathrm{~kb}$ plasmid carrying TnSha1 present either as plasmid or in an integrated form generally flanked by two IS1272 elements. The target and mechanism of integration for IS1272 and TnSha1 are novel and include targeting of DNA secondary structures, generation of blunt-end deletions of the stem-loop and absence of target duplication. Database analyses showed widespread occurrence of these two elements in chromosomes and plasmids, with TnSha1 mainly in S. aureus and with TnSha2 mainly in S. haemolyticus and S. epidermidis. The acquisition of resistance by means of an insertion sequence-based mobilization and consequent duplication of drug-target metabolic genes, as observed here for sh-fabl, is highly reminiscent of the situation with the ileS2 gene conferring mupirocin resistance, and the $d f r A$ and $d f r G$ genes conferring trimethoprim resistance both of which are mobilized by IS257. These three examples, which show similar mechanisms and levels of spread of metabolic genes linked to IS elements, highlight the importance of this genetic strategy for recruitment and rapid distribution of novel resistance mechanisms in staphylococci.

Keywords: insertion sequence, transposon, antimicrobial drug resistance, metabolism, resistance risk, fabl, IS5 family, IS1182 family 


\section{INTRODUCTION}

The NADH-dependent trans-2-enoyl-acyl carrier protein (ACP) reductase FabI is one of the highly conserved enzymes of the bacterial fatty-acids biosynthesis. The FabI enzyme has been recognized as a novel and promising candidate drug target (Payne et al., 2001; Lu and Tonge, 2008) given the absence of a eukaryotic orthologue and its essential role in the growth of bacterial cells (Heath et al., 2001; Ji et al., 2004); a concept recently challenged by the observation that some bacteria do not require biosynthesis of fatty acids during infection of the host (Brinster et al., 2009). Due to the interest in using FabI as a drug target concerns have been raised about the large scale use of the biocide triclosan which targets the active site of FabI (Schweizer, 2001; Hijazi et al., 2016); these concerns also encompass the wider risk that biocide use per se may have on antimicrobial drug resistance (Oggioni et al., 2012, 2013, 2015; Coelho et al., 2013; Maillard et al., 2013; Morrissey et al., 2014). In the specific case considered here the concern is due to the fact that resistance to triclosan is in most bacterial species mediated by mutation of the promoter region or coding sequence of fabI (Heath et al., 1999; Slater-Radosti et al., 2001; Ciusa et al., 2012; Oggioni et al., 2012; Grandgirard et al., 2015). In Staphylococcus aureus about half of resistant isolates have a novel type of triclosan resistance mechanism which is based on the presence of an alternative copy of fabI derived from Staphylococcus haemolyticus (sh-fabI) (Ciusa et al., 2012). In previous work, we reported that the sh-fabI gene appears to be part of a 3022 bp transposable element most probably mobilized by a single copy of the insertion sequence (IS) 1272 (Ciusa et al., 2012). IS1272 was originally identified in S. haemolyticus during investigation of homology matches to a truncated IS which is part of the mec cassette (Archer et al., 1994, 1996; Tonouchi et al., 1994). IS1272 is part of the IS1182 family of insertion sequences (Siguier et al., 2015) and apart from that truncated version found in the mec element is absent from $S$. aureus.

It has long been known that IS elements are able to transpose and/or change the expression of nearby or neighboring genes, that they are significantly involved in plasmid and chromosomal recombination, and that they provide the basic structure of many transposons and mobile resistance elements (Siguier et al., 2014, 2015). Soon after the discovery of ISs, it was observed that IS elements were able to transpose resistance genes between replicons (Hedges and Jacob, 1974; Barth et al., 1976). Most of the attention in the more recent sequence based work on antimicrobial resistance has still focussed on acquired "resistance"-genes which confer resistance either by target modification, inactivation of the antimicrobial compound or efflux; this is in part due to the difficulty of defining housekeeping genes identified in high throughput or metagenomic datasets as true "resistance" genes (Martinez et al., 2015). All of this "resistance"-gene oriented work has therefore overshadowed other mechanisms of resistance including those based on heterodiploidy for a metabolic gene (either resistant or susceptible alleles) which, especially in staphylococci, appears to be a mechanism with low fitness cost (Andersson, 2006; Oggioni et al., 2012). The classic example of such heterodiploidy is the presence of an additional copy of a dihydrofolate reductase $(\operatorname{dhf} A)$ gene on conjugative elements, which thereby confers resistance to trimethoprim; these include the plasmid located dhfA gene which is transposed in E. coli by Tn7 (Barth et al., 1976), the Tn4003 transposon of $S$. aureus where the $d f r A$ gene is mobilized by IS257 (Needham et al., 1995), and the more recently discovered transposable unit that comprises $d f r G$ and IS256 which is located on the Tn5801 of different species (LeónSampedro et al., 2016). A more recent example in S. aureus involves resistance to mupirocin (pseudomonic acid), a potent inhibitor of the isoleucyl tRNA synthetase; this is conferred by an additional plasmid-encoded mupA/ileS2 gene, which is again mobilized by IS257 (Gilbart et al., 1993; Woodford et al., 1998). With mupirocin, a disinfectant utilized for skin decontamination of MRSA staphylococci, this increased occurrence of mupA/ileS genes in clinical settings where mupirocin was used for decolonization has led to changes in disinfection policies (Hetem and Bonten, 2013). Even if the presence of additional mupA/ileS genes were found to confer a fitness defect to $S$. aureus, recent modeling experiments have predicted long-term increases in the prevalence of mupirocin-resistant phenotypes (MupR) given the "universal" use of mupirocin (Deeny et al., 2015).

In order to investigate the nature, sequence conservation, epidemiological distribution, and target site specificity of the 3022 bp transposable element carrying the sh-fabI gene we have sequenced the genomes of a series of triclosan resistant $S$. aureus isolates (Ciusa et al., 2012) and compared these data to the vast database of published genomes. The aims of this study were to conduct an in depth characterization of the sh-fabI carrying element, and to put this work into context with the other resistance mechanisms in $S$. aureus also based on IS mobilization of metabolic genes, which, in this species, appears to be a highly flexible means for the recruitment and rapid spread of novel resistance traits.

\section{MATERIALS AND METHODS}

\section{Bacterial Strains}

Sixty-five $S$. aureus strains with reduced susceptibility to triclosan were previously identified by performing standard MIC and MBC assays upon a collection of 1602 clinical isolates (Ciusa et al., 2012; Furi et al., 2013; Grandgirard et al., 2015; Oggioni et al., 2015). Ten out of the 28 isolates carrying the sh-fabI gene were selected from this collection for this work (Table 1; Ciusa et al., 2012).

\section{Whole Genome Sequencing and Bioinformatic Analysis}

The entire genome of $10 \mathrm{~S}$. aureus clinical isolates (Table 1) with reduced susceptibility to triclosan and positive for $s h$-fabI detection by PCR were sequenced as previously described (Ciusa et al., 2012; Table 1). Short reads were assembled using ABySS (British Columbia Cancer Agency, Vancouver, Canada; ver. 1.3.5), improved using the multi-reference based scaffolder MeDuSa (Bosi et al., 2015) and subsequent TnShal sequence identification was performed using NCBI's BLAST. 2.3.0+ (Altschul et al., 1997). The sequence of the prototype TnShal element corresponds to position 3908 to 887 of GenBank 
TABLE 1 | Relevant information of the ten sequenced S. aureus isolates (Ciusa et al., 2012).

\begin{tabular}{|c|c|c|c|c|c|c|c|}
\hline Strain & TnSha1 insertion site & MLST & Country & Year & MIC (mg/L) & MBC (mg/L) & MRSA \\
\hline QBR-102278-1091 & $\mathrm{D}$ & 12 & Japan & 2002 & 4 & 32 & MSSA \\
\hline QBR-102278-1107 & G & 1 & Australia & 2002 & 4 & 32 & MSSA \\
\hline QBR-102278-1203 & $E$ & 1 & France & 2002 & 2 & 16 & MSSA \\
\hline QBR-102278-1619 & A & 8 & Spain & 2002 & 4 & 32 & MSSA \\
\hline QBR-102278-2092 & $\mathrm{A} 2$ & 8 & Canada & 2003 & 4 & 32 & MSSA \\
\hline QBR-102278-2210 & $\mathrm{F}$ & 83 & Mexico & 2003 & 1 & 32 & MSSA \\
\hline QBR-102278-2351 & $\mathrm{A} 2$, and $\mathrm{B}$ & 3 & Brazil & 2003 & 8 & 32 & MSSA \\
\hline QBR-102278-2365 & C & 8 & Brazil & 2003 & 2 & 32 & MSSA \\
\hline QBR-102278-2376 & C & 8 & Argentina & 2003 & 4 & 32 & MSSA \\
\hline QBR-102278-2605 & $\mathrm{A} 2$ & 8 & Japan & 2003 & 32 & 64 & MRSA \\
\hline
\end{tabular}

accession JQ712986 relative to S. aureus strain QBR-1022781619. No complete sequence of TnSha2 is present in existing complete genomes in GenBank. One of the plasmid versions of TnSha2, which shows a contig break within fabI, corresponds to GenBank accession JCAZ01000023 of S. aureus strain M0227 (adzpz-supercont1.20.C23). Genbank BLAST searches for TnSha1 and TnSha2 elements were last accessed in December 2015. DNA secondary structures have been predicted by means of the RNAstructure Web Server (Reuter and Mathews, 2010). TnShal targets A through $G$ have been confirmed as gene terminator loops by direct visualization of RNAseq alignment data retrieved from the NCBI Sequence Read Archive (SRA; http://www.ncbi.nlm.nih.gov/Traces/sra/). More precisely Illumina HiSeq data which were previously generated by sequencing of whole RNA (rRNA depleted) extracted from S. aureus ATCC51811 (SRA Experiment ID: ERP005246; SRA Sample ID: ERS421566) (Fagerlund et al., 2014) were aligned to genomes of S. aureus COL, GenBank accession no. CP000046, and S. aureus MW2, GenBank accession no. BA000033, using BWA-MEM (Li, 2014). The bootstrap maximum likelihood tree was obtained using MEGA6 with default parameters. Sequence Types (ST) were defined using the Multilocus Sequence Typing (MLST) web-based service of the Center for Genomic Epidemiology (Lyngby, Denmark; MLST allele sequence and profile data were obtained from: http://pubmlst.org/; Larsen et al., 2012). Contigs containing the TnSha2 element were screened to identify plasmid sequences by means of the PlasmidFinder web-based service of the Center for Genomic Epidemiology (Ver. 1.3; Lyngby, Denmark).

\section{Molecular Analysis of Potential Transfer Intermediates}

Genomic DNA was extracted from $S$. aureus strains in the exponential phase of growth using the High Pure PCR template preparation kit (Roche Diagnostics, Germany). Prior to DNA purification the bacterial strains were grown in MHB (Muller Hinton Broth; Beckton Dickinson) in the presence of sub-MIC concentrations of triclosan (2 mg/L for strain QBR-102278-1619 and $4 \mathrm{mg} / \mathrm{L}$ for QBR-102278-2351) or following Mitomycin C induction $(1 \mu \mathrm{g} / \mathrm{L})$ (triclosan PHR1338; Sigma-Aldrich) (Ciusa et al., 2012; Oggioni et al., 2012). Negative controls grown in
MHB medium only were also used. A FAM labeled TaqMan probe was designed to detect the circular form of the IS1272 and the composite transposon TnShal when both were excised from the chromosome (Table 2). Detection of strains carrying TnSha1 in either the A or B integration sites via real-time PCR amplification was performed in a LightCycler 480 system (Roche Diagnostics, Germany) using primers annealing between the integration site and the transposon (Table 2; Oggioni et al., 2002; Isola et al., 2005; Yesilkaya et al., 2006). Primers LF_30 and LF_31 were used to detect the presence of bacteria with a transposon free integration site A (Table 2).

\section{RESULTS}

We have recently reported that a $3022 \mathrm{bp}$ chromosomal element composed of the insertion sequence IS1272 and a fabI gene of $S$. haemolyticus (sh-fabI) confers resistance to triclosan in S. aureus (Figure 1A; GenBank accession no. JQ712986) (Ciusa et al., 2012). The potential for transposition of this unit is conferred by the presence of an alternative inverted repeat (IRL') in the S. haemolyticus chromosome upstream of sh-fabI with a high degree of similarity to the inverted repeats of IS1272 (Figure 1B). This functional unit, which is composed of the insertion sequence IS1272 and the sh-fabI gene, has now being renamed TnShal (Figure 1A). It should be noted that none of our genomes, nor any deposited sequence, match the originally deposited sequence of IS1272 (Genbank accession U35635), instead all of the hundreds of IS1272 copies show at least six SNPs (four of which are indels) with respect to U35635 (Archer et al., 1996). These differences mean that the updated IS1272 element encodes for a single transposase gene without a stop codon (Figure 1A).

In this work the sequence conservation, epidemiological distribution, and target site specificity of TnShal were analyzed across a panel of ten sequenced $S$. aureus strains previously reported to carry the $s h$-fabI gene (Ciusa et al., 2012). Sequencing has identified seven different integration sites within the $S$. aureus genomes which have been named A through G (Figure 2, Table 1). The discovery of seven different TnShal integration sites in just 10 strains suggests that there is little or no insertion site preference. Analysis of the intact target sites in the reference strains COL or MW2 showed that TnShal integration always 
A

$\longmapsto$

IS1272

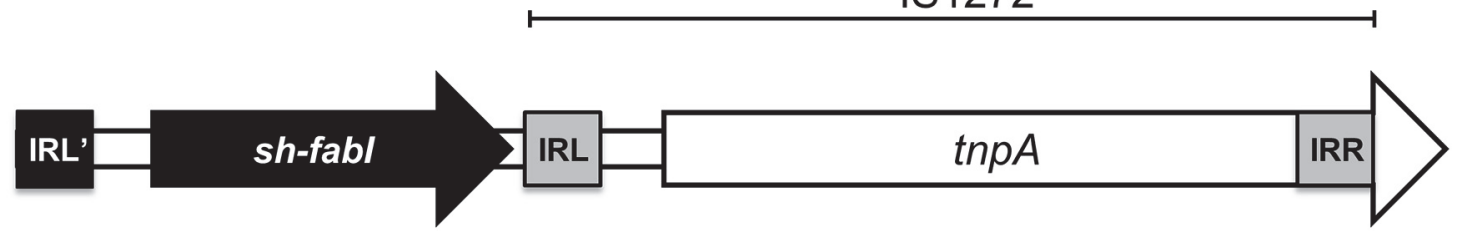

B

IRL GAGTCTGGGACATAAA

IRR GAGTCCGGGACATAAA

IRL' GGGAGTGGGACAGAAA

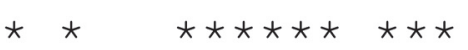

C

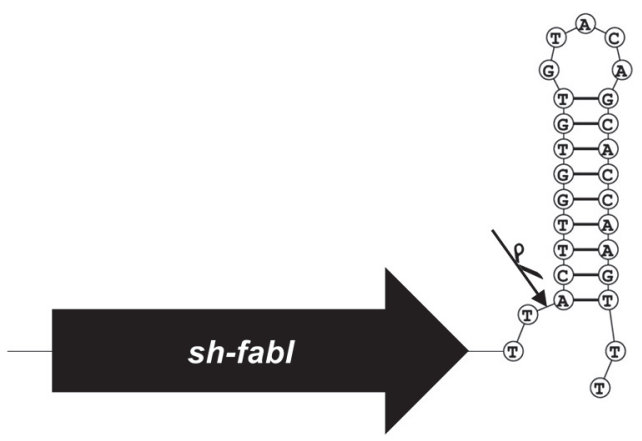

FIGURE 1 | Structure of the TnSha1 transposon. The schematic map of the composite transposon TnSha1 in which the sh-fabl gene (black) precedes the IS1272 element is shown in panel (A). The updated IS1272 sequences contains six SNPs (four of which indels) with respect to U35635 and encodes for a single transposase gene without a stop codon within the IS element. The sequence of the prototype TnSha1 element corresponds to position 3908 to 887 of Genbank accession JQ712986 relative to strain QBR-102278-1619. Panel (B) shows the inverted repeat sequences of IS1272 (named IRL and IRR) aligned to the IRL' upstream of sh-fab/ which shows 69\% identity. Panel (C) indicates the hypothesized integration event of IS1272 downstream of sh-fab/ to generate the prototype TnSha1 element in S. haemolyticus. The arrow indicates the insertion point at the base of the sh-fab/ terminator hairpin.

TABLE 2 | List of primers.

\begin{tabular}{lll}
\hline Name & Position (GenBank ID) & Sequence \\
\hline LF_26 & $\begin{array}{l}\text { Taqman probe for TnSha1 } \\
\text { (JQ712986) }\end{array}$ & $\begin{array}{l}\text { 6FAM-TTCACTTATCCAAGA } \\
\text { ACTTATGTCCCGGA-BHQ-1 }\end{array}$ \\
LF_27 & IRL' of TnSha1 (JQ712986) & $\begin{array}{l}\text { ATCCTTGCCGGGGTAAT } \\
\text { ACAAC }\end{array}$ \\
LF_28 & IRL of TnSha1 (JQ712986) & AAAGCGAGCCAACAATACG \\
& & GAGTA \\
LF_29 & IRR of TnSha1 (JQ712986) & TAGTAGCTCAACGAGCTGA \\
& & AAATAATC \\
LF_30 & Upstream region flanking the TnSha1 & TTGATTATTCCCAGCCTATT \\
& integration site A A2 (NC_002951) & CTITCA \\
LF_31 & Downstream region flanking the TnSha1 & AGGATGTCGATTGATTAT \\
& integration site AA2 (NC_002951) & ATITITGTACAT \\
LF_32 & Downstream region flanking the & ATCATTCGTTATATATAGCA \\
& TnSha1 integration site B (NC_002951) & GACATGATAGA
\end{tabular}

occurs into hairpin structures and, importantly, that the mode of insertion of TnShal always produces a partial deletion of the target sequence (Figure 2B). This mode of integration into the stem of secondary structures is novel to IS elements (Siguier et al., 2015). For one of the targets sequenced in this work there were two different transposition events which could be detected; these lead to deletions of different sizes in the same target site (A and A2; Figure 2B). All seven of the target sites identified by sequencing of our clinical isolates, in addition to other sites subsequently identified in published sequences, were composed of inverted repeat sequences and thus have the potential to form secondary structures with the repeats representing the stems of hairpins (Figure 2A). In each case insertion of TnShal produced a partial deletion of the hairpin. This type of cleavage of a secondary structure forming sequences appears to indicate that TnShal makes blunt and not staggered cuts, which would have resulted in target duplications. Hairpins A through E have been 
A
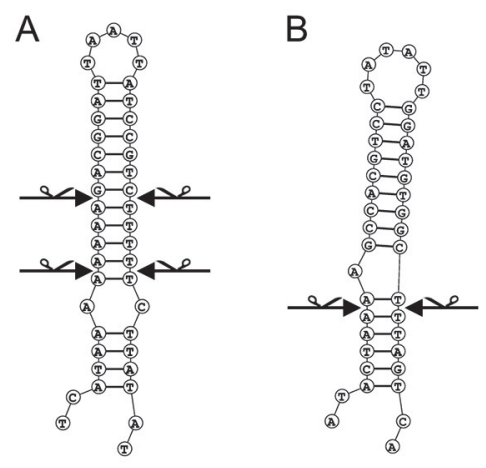

D

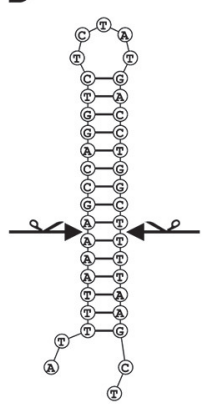

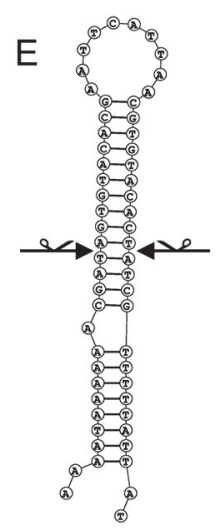

B

$\begin{array}{ll}\text { A) } & \text { S. aureus COL } \\ \text { A2) } & \text { S. aureus COL } \\ \text { B) } & \text { S. aureus COL } \\ \text { C) } & \text { S. aureus COL } \\ \text { D) } & \text { S. aureus JKD6159 } \\ \text { E) } & \text { S. aureus MW2 } \\ \text { F) } & \text { S. aureus MW2 } \\ \text { G) } & \text { S. aureus MW2 }\end{array}$

S. aureus MW2

P) S. haemol. p25-44

V) S. aureus pTW20_1

W) S. aureus pWGB $7 \overline{4} 5$

X) S. aureus pSA1379

Y) S. epid. pSAP108A

Z) S. aureus PUSA03
C

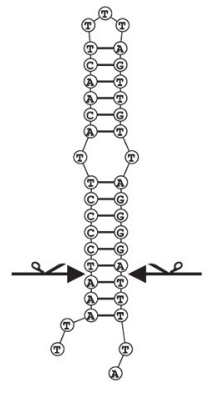

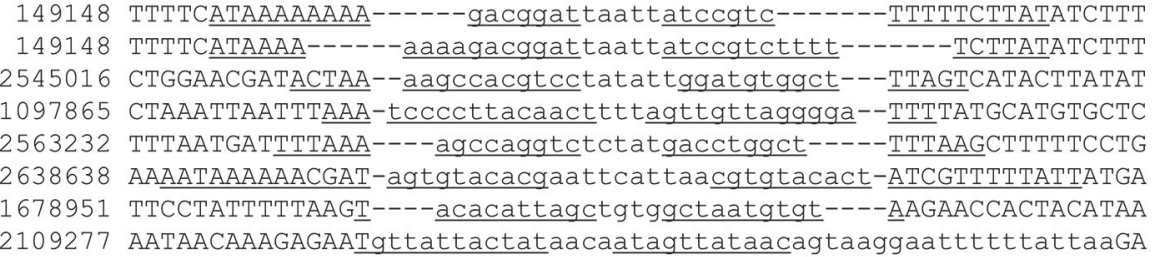

5401 TTAGGTTAAAAGAAA---ggagctaacctttagggttagctcC----TTTCTGTGTTCTTTAT 13941 CTTAATAATAAAAAA-gtagaaccatttaaattaatggttctac--TTTTTAACTATTACTA 22280 ATTTTACAAATAAA---aagaaagtgattatatcactttctt----TCCTTAACTATACGAT

20646 TACTTAATAATAAAAaagtagaaccatttaaattaatggttctactTTTTAACTATTACTAA

12204 TATTCAAAAAAAAATaatgtattcacgcctaagggcgtgaatacattATTTTCTCTAAAAAGA

1076 TTTCAAAAAAAAGAG---attatacacctaaaaggtgtataat---CTTTACGGTTCTGTTG

C
LPIH 6008
F77919
TAAATTTTCAAAAAAAAGAGGGGAGTGGGNNNNNNNNCCCGGACTCCTTTACGGTTCTGTTGCAAA
W21 479 TAAATTTTCAAAAAAAAGAGGGGAGTGGGNNNNNNNNCCCGGACTCCTTTACGGTTCTGTTGCAAA
HOAG 6084 TAAATTTTCAAAAAAAAGAGGGGAGTGGGNNNNNNNNCCCGGACTCCTTTACGGTTCTGTTGCAAA TAAATTTTCAAAAAAAAG--GGGAGTGGGNNNNNNNNCCCGGACTC-TTTACGGTTCTGTTGCAAA
F70077
F12753
TAAATTTTCAAAAAAAAGA-GAGTCCGGGNNNNNNNNCCCACTCCCCTTTACGGTTCTGTTGCAAA
F12753 IAAATTTTCAAAAAAAAGA-GAGTCCGGGNNNNNNNNCCCACTCCCCTTTACGGTTCTGTTGCAAA
target TAAATTTTCAAAAAAAAGA-GAGTCCGGGNNNNNNNNCCCACTCCC-TTTACGGTTCTGTTGCAAA
TAAATTTTCAAAAAAAAGAGATTATACACCTAAAAAGGTGTATAATCTTTACGGTTCTGTTGCAAA $* * * * * * * * * * * * * * * * * * *$ $\star * * * * * * * * * * * * * * * * *$

FIGURE 2 | Insertion sites of TnSha1 in bacterial chromosomes and plasmids. The seven target sites found in the $10 \mathrm{~S}$. aureus strains sequenced in this work have been named from A to $G$. Staphylococcal plasmid insertion sites are named P to Z. Panel (A) shows the hairpin structures formed by the transposon target sites and the scissors indicate the position of sequence breaks generated upon TnSha1 insertion. Secondary structure predictions were made using RNAstructure web-based software (Reuter and Mathews, 2010). Two independent insertions into target (A) have been identified and both cleavage sites are shown which in each case generate blunt-end structures in the stem of the hairpin. The sequences in both panels $(\mathbf{A}, \mathbf{B})$ refer to TnSha1-free target sites in the chromosomes (COL GenBank accession CP000046 and MW2 GenBank accession BA000033) and plasmids. The target sequences in panel (B) report in lower case the sequence deleted upon insertion and the inverted repeats underlined. Panel (C) shows evidence for multiple insertions of TnSha1 in target $Z$ in the repA terminator of plasmids. The aligned sequences show at least four independent insertions in two opposite orientations of TnSha1 into the repA terminator in plasmid pUSA03 (target Z). In this panel TnSha1 sequences are shown in bold italics upper case, the deleted part of the target sequence in lower case, and the repA terminator hairpin underlined. Note that in panel (C) the upper four TnSha1 sequences are in one orientation while the lower three in the opposite orientation. Note that in panel (C) the upper four TnSha1 sequences are in one orientation while the lower three in the opposite orientation. The S. aureus strain names are given on the right.

confirmed as transcriptional terminators by mapping of RNAseq data (Fagerlund et al., 2014; Figure 3). When analysing the target sites of a further 63 complete TnShal elements from published S. aureus genomes, we identified an additional 12 target sites confirming a lack of any primary sequence specificity within the target. All of the aforementioned features of TnShal are consistent with the known behavior of the IS1272 element alone (Archer et al., 1996); i.e., such as the insertion of IS1272 which occurred into the terminator of $s h$-fabI to generate the prototype TnSha1 (Figure 1C), or as in the case of two target sites selected from IS1272 insertions in the genomes of S. haemolyticus or S. warneri (Figure 4). While most sequenced strains contained 


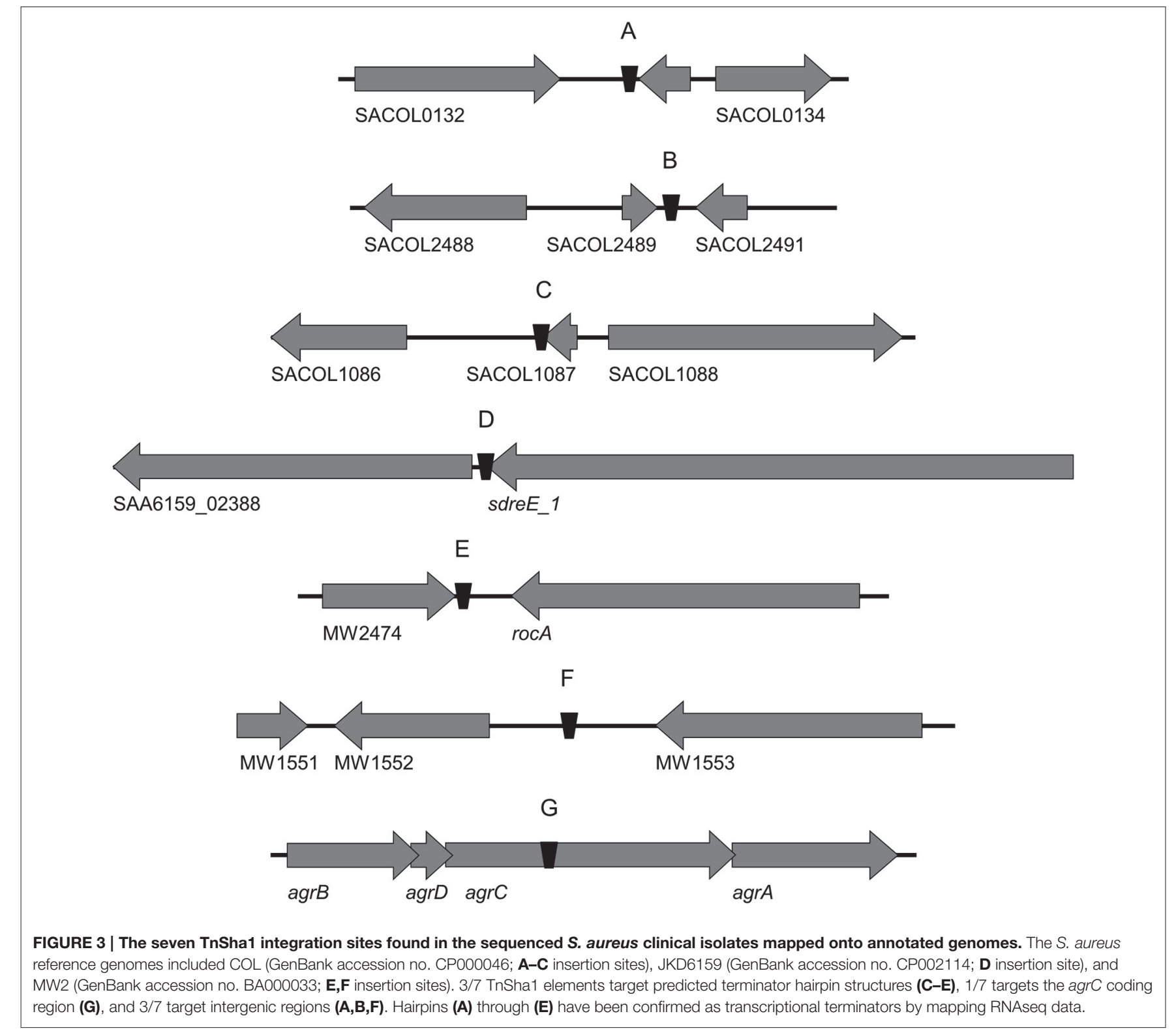

just a single copy of TnShal in the chromosome, strain QBR102278-2351 was an exception and carried two TnSha1 elements each in two distinct integration sites (Figure 2, Table 1).

The dynamics and epidemiology of transposition between strains was addressed by searching for other TnShal elements present in Genbank. Database searches identified 133 complete or partial TnShal elements in the genomes of the species $S$. aureus, S. argenteus, S. haemolyticus, S. epidermidis, S. saprophyticus, and $S$. warneri, and in a series of staphylococcal plasmids (Tables 3-5). Of this latter group the integration between repA and IS257 in pUSA03 (target Z in Table 4) where TnShal was inserted in two different orientations warrants particular attention (Figure 2C). Multi locus sequence typing (MLST) of the strains showed that TnShal was present in $S$. aureus in sequence type $8(n=23)$, ST5 $(n=18)$, ST239 $(n=6)$, and
ST290 $(n=6)$ strains and in S. epidermidis in ST59 $(n=10)$ and ST2 $(n=6)$ strains (Table 4, Figure 5). Upon determination of the targets of these newly identified TnShal elements it was found that only seven out of the 66 complete TnShal elements were integrated into the same seven target sites, A to $G$, that we had previously identified (Figure 2, Tables 1, 4). Alignment of our previous 10 TnShal elements with the seven new TnShal elements that were integrated at the same target sites showed clustering of the TnSha1-SNPs (some elements differed by up to 11 SNPs from the consensus) together with their target sites (Figure 6). This pattern is consistent with the insertion of the element into a particular target followed by clonal spread. This scenario appears to be the rule in most cases except for target A2 and $\mathrm{Z}$ where the identical TnShal element is present in the same target but in strains of different ST (Table 4, Figure 5). To test for 
A

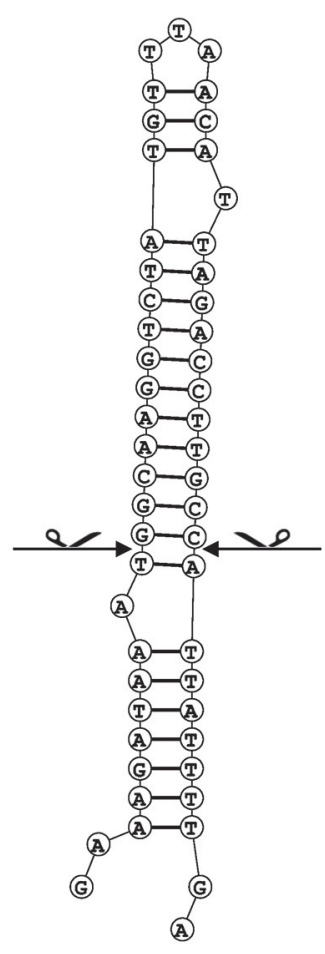

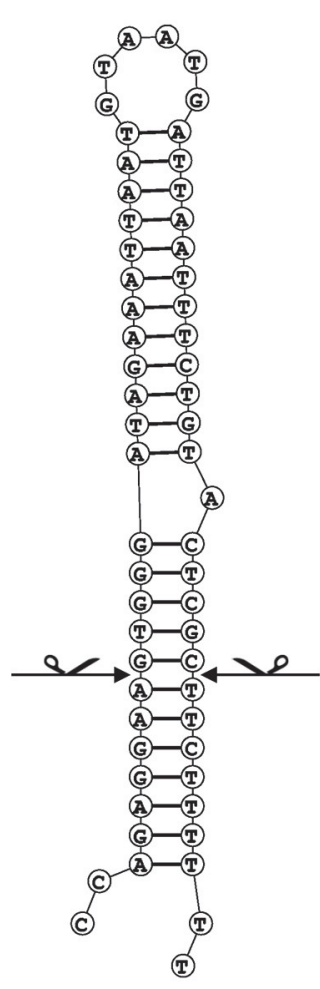

B

S. warneri VCU121

S. haemolyticus R1P1
GAAAGATAAAT----ggcaaggtctatgtttaacattagaccttgcc-----ATTATTTTGAC TTCCAGAGGAAgtgggatagaaattaatgtaatgattaatttctgtactcgcTTCTTTTTTAT

FIGURE 4 | Analysis of target sites of IS1272 in S. warneri and S. haemolyticus. Secondary structure predictions of the IS1272 targets in the S. warneri strain SG1 (GenBank accession CP003668) are shown in the IS free reference strain VCU121 (GenBank accession NZ_AFEC01000030) (A left); and in the S. haemolyticus strain Sh29/312/L2 (GenBank accession CP011116) are shown in the IS free reference strain R1P1 (GenBank accession NZ_AJVA00000000) (A right). The exact blunt target cleavage sites are indicated by scissors. Panel (B) indicates the target sequences showing the inverted repeats (underlined) and deletions (lower case).

TABLE 3 | BLAST search of staphylococcal genomes for TnSha1 and TnSha2.

\begin{tabular}{|c|c|c|c|c|c|c|}
\hline Species & Element & Chromosomal $^{\star}$ & Plasmid $^{\star \star}$ & Total & Total number of genomes & $\%$ \\
\hline \multirow[t]{2}{*}{ S. argenteus } & TnSha1 & 1 & 1 & 2 & 6 & 33 \\
\hline & TnSha2 & - & - & - & & - \\
\hline S. aureus & TnSha2 & 1 & - & 1 & & 0.02 \\
\hline S. epidermidis & TnSha1 & 30 & 1 & 31 & 286 & 10.8 \\
\hline S. haemolyticus & TnSha2 & 10 & - & 10 & & 7 \\
\hline \multirow[t]{2}{*}{ S. warneri } & TnSha1 & 2 & - & 2 & 7 & 28.6 \\
\hline & TnSha2 & - & - & - & & - \\
\hline \multirow[t]{2}{*}{ S. saprophyticus } & TnSha1 & 1 & - & 1 & 5 & 20 \\
\hline & TnSha2 & - & - & - & & - \\
\hline
\end{tabular}

*The localization designated as chromosomal may also include plasmids present in genome contigs. **Only includes plasmids deposited as complete plasmids. 
TABLE 4 | List of strains carrying the TnSha1 element on the chromosome.

\begin{tabular}{|c|c|c|c|c|}
\hline Species & GenBank ID & Strain name & $\begin{array}{l}\text { Insertion } \\
\text { site }\end{array}$ & MLST \\
\hline S. argenteus & CCEM01000001 & Sa_LBSA043 & M & - \\
\hline S. aureus & AIDT01000009 & DR10 & $\mathrm{H}$ & 398 \\
\hline S. aureus & AUPV01000018 & $\mathrm{S} 100$ & $\mathrm{H}$ & 398 \\
\hline S. aureus & CAVU010000033 & S1805 & $E$ & 80 \\
\hline S. aureus & CAWA010000053 & S2396 & $E$ & 1 \\
\hline S. aureus & CFPN01000018 & USFL079 & L & 8 \\
\hline S. aureus & CGGX01000004 & USFL145 & A & 8 \\
\hline S. aureus & CIAK01000002 & USFL234 & J & 8 \\
\hline S. aureus & CIGG01000001 & USFL129 & C & 8 \\
\hline S. aureus & СР003045 & 71193 & $\mathrm{H}$ & 398 \\
\hline S. aureus & CSDA01000011 & USFL101 & L & 8 \\
\hline S. aureus & CSDP01000002 & USFL046 & J & 8 \\
\hline S. aureus & CSEJ01000001 & USFL123 & C & 8 \\
\hline S. aureus & CSEV01000003 & USFL189 & A2 & 828 \\
\hline S. aureus & CSFL01000012 & USFL078 & L & 8 \\
\hline S. aureus & CSHX01000003 & USFL190 & A2 & 828 \\
\hline S. aureus & CSJZ01000023 & USFL050 & nd & $8 \mathrm{slv}^{\star}$ \\
\hline S. aureus & CTWU01000023 & M705 & K & 239 \\
\hline S. aureus & CTWW01000088 & $\mathrm{H} 211$ & K & 239 \\
\hline S. aureus & СТХO01000001 & M1229 & $\mathrm{K}$ & 239 \\
\hline S. aureus & CTXZ01000061 & $\mathrm{H} 216$ & $\mathrm{~K}$ & 239 \\
\hline S. aureus & CTYD01000081 & $\mathrm{H} 2 \mathrm{O} 2$ & K & 239 \\
\hline S. aureus & CVOP01000018 & $\mathrm{SH} 3$ & M & 630 \\
\hline S. aureus & CVOU01000018 & $\mathrm{SH} 1$ & M & 630 \\
\hline S. aureus & CVRW01000028 & M170 & K & 239 \\
\hline S. aureus & JBFG01000011 & KINW6058 & 1 & 5 \\
\hline S. aureus & JBGB01000006 & FVRH6130 & nd & 8 \\
\hline S. aureus & JBGS01000014 & GGMC6026 & 1 & 5 \\
\hline S. aureus & JBLE01000006 & SCOA6048 & $\mathrm{H}$ & 8 \\
\hline S. aureus & JBMX01000012 & SCOA6012 & $\mathrm{H}$ & 8 \\
\hline S. aureus & JDLS01000019 & T78544 & 1 & 5 \\
\hline S. aureus & JDOK01000060 & F35307 & nd & 5 \\
\hline S. aureus & JDOU01000017 & H27862 & I & 5 \\
\hline S. aureus & JDOV01000017 & H27872 & 1 & 5 \\
\hline S. aureus & JDPI01000020 & H67656 & I & 5 \\
\hline S. aureus & JECS01000014 & T34011 & 1 & 5 \\
\hline S. aureus & JEDV01000017 & H64967 & I & 5 \\
\hline S. aureus & JETJ01000039 & T22051 & nd & 5 \\
\hline S. aureus & JGNE01000030 & W41757 & nd & 5 \\
\hline S. aureus & JHTT01000046 & CO-86 & L & 8 \\
\hline S. aureus & JIXI01000011 & PA57 & $\mathrm{H}$ & 398 \\
\hline S. aureus & JIYX01000004 & C5086 & $\mathrm{H}$ & $398 \mathrm{slv}$ \\
\hline S. aureus & JJDE01000001 & 122 & $\mathrm{H}$ & 398 \\
\hline S. aureus & JURB01000090 & 84_SAUR & $\mathrm{F}$ & 5 \\
\hline S. aureus & JUTG01000033 & 78_SAUR & $\mathrm{F}$ & 5 \\
\hline S. aureus & JVUC01000150 & 1315_SAUR & nd & 15 \\
\hline S. aureus & JZAL01000002 & LHSKBClinical & C & 8 \\
\hline S. aureus & LAMP01000014 & $99-06$ & L & 8 \\
\hline S. aureus & LAMS01000038 & $99-48$ & L & 8 \\
\hline S. epidermidis & ACHE01000003 & ВСМ-HMP0060 & - & 59 \\
\hline
\end{tabular}

(Continued)
TABLE 4 | Continued

\begin{tabular}{|c|c|c|c|c|}
\hline Species & GenBank ID & Strain name & $\begin{array}{l}\text { Insertion } \\
\text { site }\end{array}$ & MLST \\
\hline S. epidermidis & AGUC01000094 & 14.1.R1.SE & - & - \\
\hline S. epidermidis & AHLC01000060 & VCU120 & - & 22 \\
\hline S. epidermidis & AHLF01000017 & VCU125 & - & 384 \\
\hline S. epidermidis & AKGM01000041 & NIHLM067 & - & 333 \\
\hline S. epidermidis & AKGN01000056 & NIHLM061 & - & 332 \\
\hline S. epidermidis & AKGW01000049 & NIHLM020 & - & 7 \\
\hline S. epidermidis & APHT01000038 & $528 m$ & - & 2 \\
\hline S. epidermidis & APHU01000037 & $41 \mathrm{tr}$ & - & 2 \\
\hline S. epidermidis & ARWU01000031 & UC7032 & - & 595 \\
\hline S. epidermidis & JUMV01000141 & 938_SEPI & - & 59 \\
\hline S. epidermidis & JUNI01000550 & 926_SEPI & - & 59 \\
\hline S. epidermidis & JUVK01000069 & 73_SEPI & - & 16 \\
\hline S. epidermidis & JUYJ01000034 & 655_SEPI & - & 59 \\
\hline S. epidermidis & JUYK01000190 & 654_SEPI & - & 59 \\
\hline S. epidermidis & JVQK01000079 & 196_SEPI & - & 59 \\
\hline S. epidermidis & JVSC01000077 & 154_SEPI & - & 59 \\
\hline S. epidermidis & JVSC01000077 & 154_SEPI & - & 59 \\
\hline S. epidermidis & JVSZ01000046 & 134_SEPI & - & 59 \\
\hline S. epidermidis & JVTV01000122 & 1321_SEPI & - & 59 \\
\hline S. epidermidis & JWBR01000039 & 114_SEPI & - & - \\
\hline S. epidermidis & JWCR01000091 & 1115_SEPI & - & 88 \\
\hline S. epidermidis & JWEH01000024 & 1063_SEPI & - & 2 \\
\hline S. epidermidis & JWFU01000070 & 1024_SEPI & - & 2 \\
\hline S. epidermidis & JWFV01000104 & 1023_SEPI & - & 2 \\
\hline S. epidermidis & JZUK01000044 & NGS-ED-1107 & - & 2 \\
\hline S. epidermidis & JZUL01000024 & NGS-ED-1109 & - & 439 \\
\hline S. haemolyticus & СР011116 & Sh29/312/L2 & - & - \\
\hline S. haemolyticus & CUEZ01000014 & CN1197 & - & - \\
\hline S. saprophyticus & JXBG01000015 & SU8 & - & - \\
\hline S. warneri & CANQ01000015 & A487 & - & - \\
\hline S. warneri & JPOW01000002 & NGS-ED-1001 & - & - \\
\hline
\end{tabular}

*s $\mathrm{V}$ = single locus variant; targets $A-G$ from our genome sequences; targets $H-Z$ from Genbank, nd not determined.

TnSha1 mobilization we used PCR with a set of divergent primers on TnSha1, another set on IS1272, and a third set of primers targeting the "A" insertion site. Unfortunately, no excision events producing a circular intermediate could be observed when two $S$. aureus strains were tested with or without the presence of triclosan in the culture medium, and after induction with mitomycin C.

Within the multiple entries retrieved from Genbank a subgroup showed identical sequences upstream of TnShal. Investigation of this genomic region showed that in 30 of the strains the TnShal element forms part of a larger element (named TnSha2), which in almost all cases is a plasmid, but which can also be found integrated into the genome where it is generally flanked by a second copy of IS1272 (Tables 4, 5). The prototype sequence of TnSha2 (S. aureus JCAZ01000023) is an $11.7 \mathrm{~kb}$ plasmid in which TnShal is inserted into the terminator of traQ gene of an $8.7 \mathrm{~kb}$ replicon (without fabI and IS1272) 
TABLE 5 | List of strains carrying the TnSha1 element on a plasmid.

\begin{tabular}{|c|c|c|c|c|c|}
\hline Species & GenBank ID & Strain name & Plasmid & Insertion site & MLST \\
\hline S. argenteus & FR821778 & MSHR1132 & pST75 & $\mathrm{X} 2$ & - \\
\hline S. aureus & AHVE01000013 & ClG1165 & Plasmid & $x$ & 5 \\
\hline S. aureus & CP012121 & USA300_2014.C02 & pUSA300_2014.C02 & $x$ & 8 \\
\hline S. aureus & СP012594 & HOU1444-VR & pVR-MSSA_01 & W & 5 \\
\hline S. aureus & CSBT01000019 & USFL338 & Plasmid & V & 8 \\
\hline S. aureus & JBGG01000015 & LAMC6115 & Plasmid & Zrc & 8 \\
\hline S. aureus & JBJX01000010 & SJUD6114 & Plasmid & $x$ & 8 \\
\hline S. aureus & JBRD01000004 & AMMC6015 & Plasmid & Z & 8 \\
\hline S. aureus & JBSH01000015 & HOAG6084 & Plasmid & Z & 8 \\
\hline S. aureus & JCAZ01000023 & M0227 & TnSha2 & $P$ & 5 \\
\hline S. aureus & JDXZ01000007 & LPIH6008 & Plasmid & Z & 8 \\
\hline S. aureus & JEEN01000028 & F77919 & Plasmid & Z & 5 \\
\hline S. aureus & JEOI01000012 & W21479 & Plasmid & Z & 5 \\
\hline S. aureus & JEQM01000030 & F70077 & Plasmid & $\mathrm{Zrc}$ & 5 \\
\hline S. aureus & JGFR01000050 & F12753 & Plasmid & Zrc & 5 \\
\hline S. aureus & JGIT01000028 & T28653 & Plasmid & $x$ & 8 \\
\hline S. aureus & JICL01000103 & 880 & pHMPREF1625_3 & W & - \\
\hline S. aureus & JVUX01000076 & 1299_SAUR & Plasmid & Z & 2250 \\
\hline S. epidermidis & GQ900465 & SK6536 & pSAP110A & $\mathrm{Y}$ & - \\
\hline S. epidermidis & JUPD01000185 & 890_SEPI & TnSha2 & $P$ & 2 \\
\hline S. epidermidis & JUUP01000151 & 749_SEPI & TnSha2 & $\mathrm{P}$ & 2 \\
\hline S. epidermidis & JUYI01000150 & 656_SEPI & TnSha2 & $P$ & 2 \\
\hline S. epidermidis & JUZG01000070 & 634_SEPI & TnSha2 & $\mathrm{P}$ & 2 \\
\hline S. epidermidis & JUZR01000081 & 623_SEPI & TnSha2 & $\mathrm{P}$ & 2 \\
\hline S. epidermidis & JVBT01000060 & 568_SEPI & TnSha2 & $\mathrm{P}$ & 2 \\
\hline S. epidermidis & JVHA01000086 & 439_SEPI & TnSha2 & $\mathrm{P}$ & 2 \\
\hline S. epidermidis & JVHR01000056 & 422.rep2_SEPI & TnSha2 & $P$ & 2 \\
\hline S. epidermidis & JVHS01000079 & 422.rep1_SEPI & TnSha2 & $\mathrm{P}$ & 2 \\
\hline S. epidermidis & JVKK01000090 & 354_SEPI & TnSha2 & $P$ & 2 \\
\hline S. epidermidis & JVXB01000116 & 1249_SEPI & TnSha2 & $\mathrm{P}$ & 2 \\
\hline S. epidermidis & JWBN01000071 & 1143_SEPI & TnSha2 & $\mathrm{P}$ & 2 \\
\hline S. epidermidis & JWDK01000004 & 1088_SEPI & TnSha2 & $\mathrm{P}$ & 2 \\
\hline S. epidermidis & JWFS01000043 & 1026_SEPI & TnSha2 & $\mathrm{P}$ & 2 \\
\hline S. epidermidis & JWFW01000102 & 1022_SEPI & TnSha2 & $\mathrm{P}$ & 2 \\
\hline S. epidermidis & JWFX01000149 & 1021.rep2_SEPI & TnSha2 & $\mathrm{P}$ & 2 \\
\hline S. epidermidis & JWFY01000144 & 1021.rep1_SEPI & TnSha2 & $\mathrm{P}$ & 2 \\
\hline S. epidermidis & JWGH01000004 & 1013_SEPI & TnSha2 & $\mathrm{P}$ & 2 \\
\hline S. epidermidis & JWGL01000037 & 101_SEPI & TnSha2 & $P$ & 2 \\
\hline S. haemolyticus & CUCK01000025 & $25-38$ & TnSha2 in chromosome* & $\mathrm{P}$ & 29 \\
\hline S. haemolyticus & CUCN01000051 & $25-60$ & TnSha2 & $P$ & - \\
\hline S. haemolyticus & CUCZ01000051 & $51-13$ & TnSha2 & $P$ & 3 \\
\hline S. haemolyticus & CUDB01000007 & $51-11$ & TnSha2 in chromosome & $\mathrm{P}$ & 3 \\
\hline S. haemolyticus & CUDQ01000054 & $51-33$ & TnSha2 & $\mathrm{P}$ & 3 \\
\hline S. haemolyticus & CUDW01000051 & $51-41$ & TnSha2 & $P$ & 2 \\
\hline S. haemolyticus & CUDY01000029 & $51-43$ & TnSha2 in chromosome & $\mathrm{P}$ & 2 \\
\hline S. haemolyticus & CUFB01000040 & $51-15$ & TnSha2 & $\mathrm{P}$ & 3 \\
\hline S. haemolyticus & CUGD01000039 & 127925 & TnSha2 in chromosome & $\mathrm{P}$ & 3 \\
\hline S. haemolyticus & CUGG01000054 & 113101 & TnSha2 & $\mathrm{P}$ & 3 \\
\hline
\end{tabular}

${ }^{*}$ Chromosomally integrated TnSha2 elements are reported for clarity in this plasmid table. 


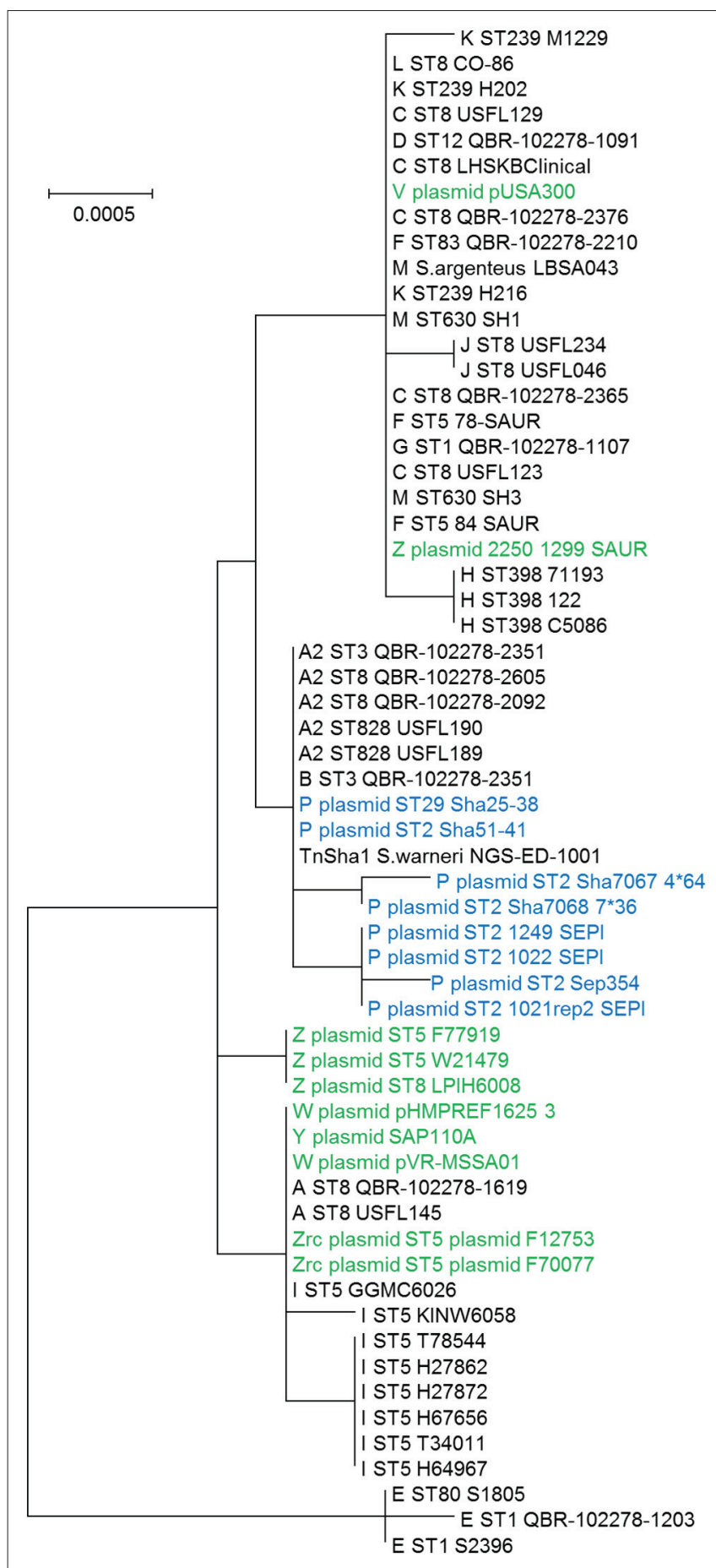

FIGURE 5 | Phylogram of the TnSha1 and TnSha2 elements. The tree contains 57 TnSha1 sequences, 10 of which sequenced in this work (QBR-102278 sequences) and a subset of eight TnSha2 sequences (only the homologous part was used for tree building purposes). Each TnSha1 element is identified by its target (A-Z), followed by the sequence type (ST), and the strain name. TnSha1 elements on S. aureus plasmids are colored in green while TnSha2 elements are in blue. For GenBank accession numbers please see Tables 1, 4. The bootstrap maximum likelihood tree was obtained using MEGA6 with default parameters. The scale bar is shown in the upper left part. It should be noted that the tree is built based on only few SNPs, which distinguish the different elements.

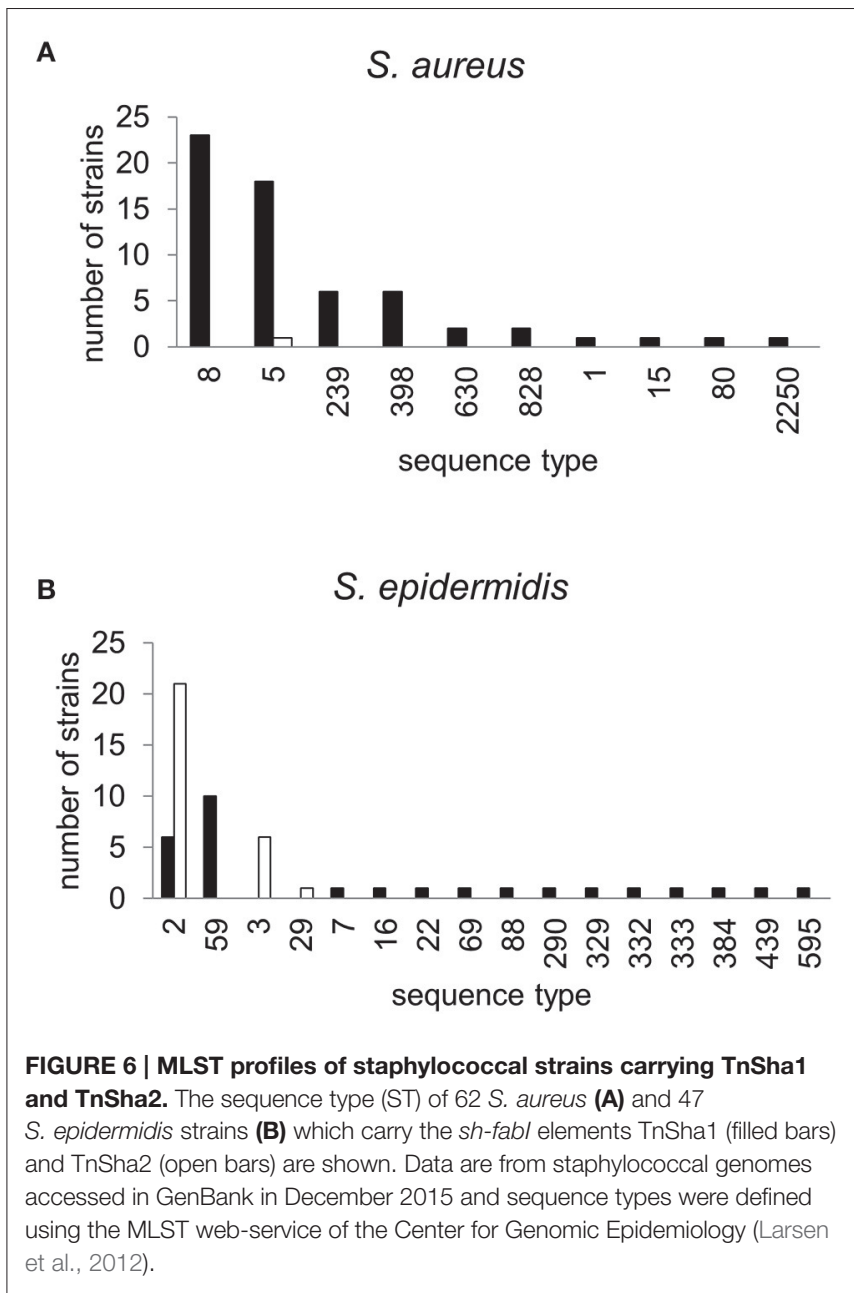

present in S. haemolyticus (CUCL01000044), but also in S. aureus (JJAQ010000025; Figure 7). The rep of the plasmid belongs to the Rep_2 family and the DNA polymerase, recombinase and mobilization protein show high sequence identity to those of plasmid p-12228-03 of the S. epidermidis reference strain ATCC 12228 (Figure 7; Zhang et al., 2003; Lanza et al., 2015). ThSha2 was detected in the genomes of clonally diverse S. haemolyticus, and S. epidermidis (ST3 $n=6$, and ST2 $n=21$, respectively), but only in a single $S$. aureus (ST5) genome, thereby reflecting different dissemination routes for different species (Table 5). Upon investigating the origin of deposited genome-strains it was observed that the S. epidermidis ST2 strains are of hospital origin (Schoenfelder et al., 2010; Roach et al., 2015) and that all of the S. haemolyticus strains with TnSha2 and ST3 that we found in this study are clinical isolates (Table 5). Interestingly the database search for IS1272 alone detected no intact elements in S. aureus, but did show that about $1 / 10$ of $S$. epidermidis isolates and the majority of $S$. haemolyticus isolates carried IS1272 thereby ensuring that the contigs with the $11.7 \mathrm{~kb}$ plasmid in these species are always interrupted in the IS element.

In a phylogenetic tree based on the TnSha1-part of TnSha2, the two elements group into separate branches due to a series of SNPs both in fabI and the IS1272 element (Figure 5). In 
A

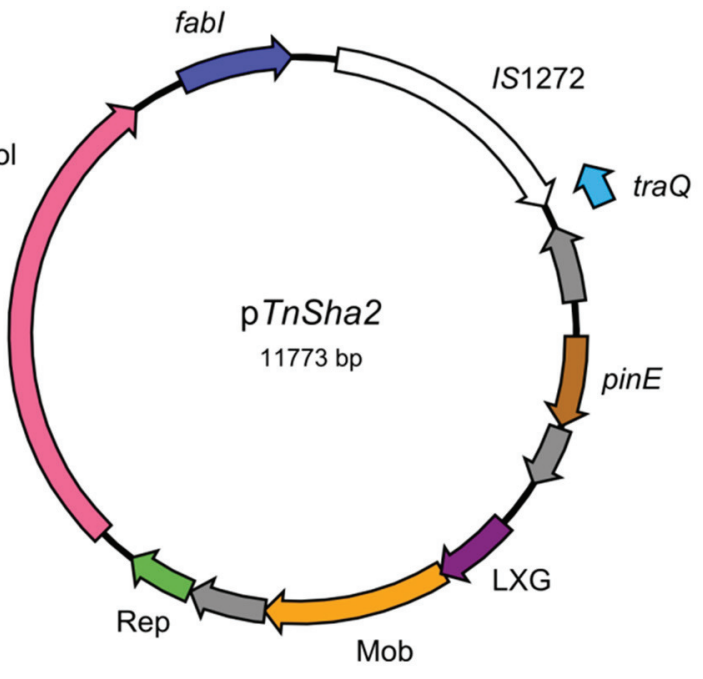

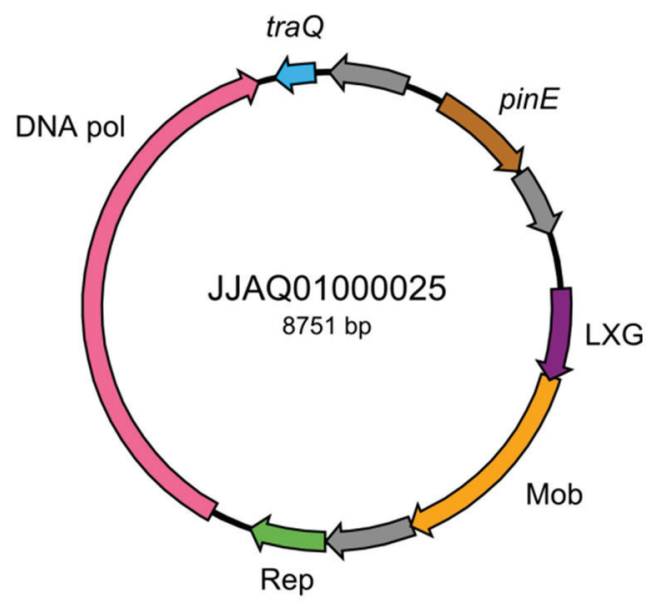

B

IS1272 traQ pinE LXG mob

rep DNA pol

fabl IS1272

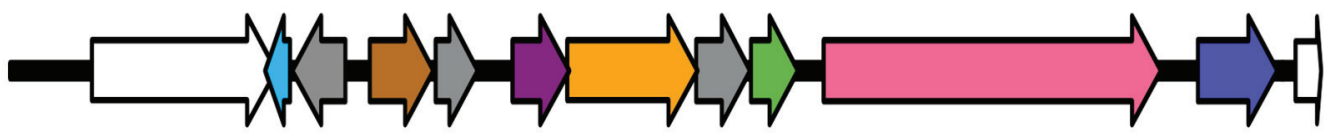

pTnSha2

C

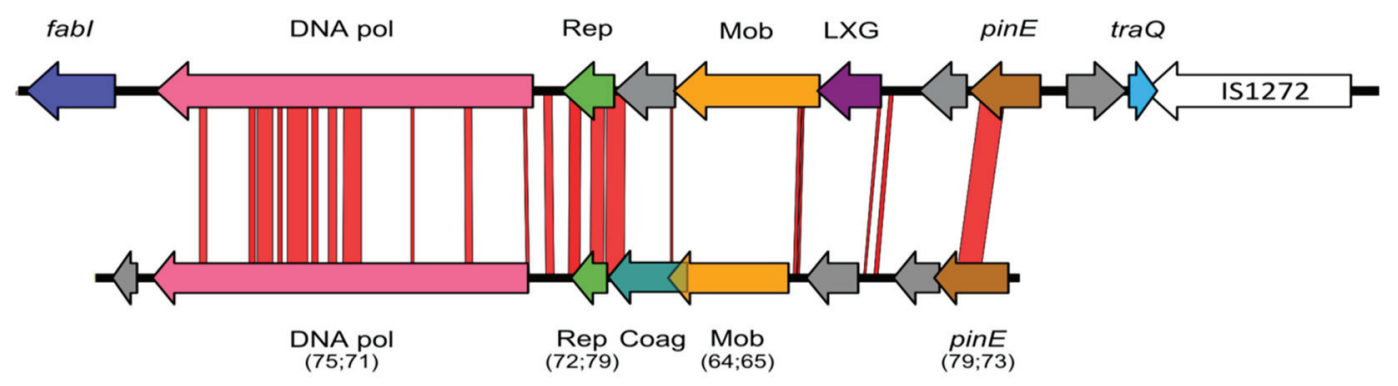

pSE-12228-03

8,007 bp

FIGURE 7 | Schematic map of TnSha2 elements. The circular maps of the prototype $11.7 \mathrm{~kb}$ plasmid sequence of TnSha2 (S. aureus strain M0227, GenBank accession JCAZ01000023) and the target $8.7 \mathrm{~kb}$ TnSha1-free plasmid (S. haemolyticus CUCL01000044 or S. aureus JJAQ010000025) are shown in panel (A). The map of TnSha2 integrated into the S. haemolyticus chromosome at a position occupied by a single IS1272 in the reference strain is shown in panel (B). In three occasions the resulting chromosomal island is bordered by two IS1272 elements (CUCK01000025 at position 590129 of strain JCSC1435, CUDY01000029 at 1828271, and CUGD01000039 at 2443315) wile in one case only by the "left" IS1272 element (CUDB01000007 at 1322312). Comparison between pTnSha2 element (S. aureus JCAZ01000023) and pSE-12228-03 (S. epidermidis NC_005006) is shown in panel (C). Numbers between brackets indicate coverage percentage and identity percentage respectively. The genes encode for: a putative DNA-directed DNA polymerase (DNA pol), a replication protein involved in a theta-type replication mechanism (Rep), a putative mobilization protein (Mob), a domain of a group of polymorphic toxin proteins (LXG), a Site-specific DNA recombinase related to the DNA invertase Pin (PinE), and a conjugal transfer pilin chaperone (TraQ). 
four cases the whole $11.7 \mathrm{~kb}$ TnSha2 plasmid appears to be integrated into the chromosome of S. haemolyticus in the same position that IS1272 elements are found in reference strain JCSC1435 resulting in a chromosomal island flanked in three cases by two IS1272 copies (CUCK01000025 at position 590.150 of JCSC1435, CUDB01000007 at 1.322.311, CUDY01000029 at 1.828.279, and CUGD01000039 at 2.443.339; Figure 7; Cavanagh et al., 2014).

In the original publication, which described sh-fabI in S. aureus QBR-102278-1619 (Ciusa et al., 2012), the TnShal element was reported to carry a sh-fabI gene with an A577T SNP with respect to the sequence of the core genome fabI of S. haemolyticus (Table 6). Since, this SNP had not previously been associated with triclosan resistance of $s a-f a b I$ in $S$. aureus the gene was reported to represent a susceptible allele (Ciusa et al., 2012). Whilst analysing the panel of sh-fabI genes carried by TnShal these were all found to show at least one SNP compared to the core-genome triclosan-susceptible sh-fabI of S. haemolyticus (Table 6). All of these SNPs, except A577T and T578A (see above), have previously been associated with triclosan resistance in the S. aureus sa-fabI (Table 6; Ciusa et al., 2012; Grandgirard et al., 2015). The only exception is $S$. aureus strain T22051 which carried a wild type sh-fabI gene in TnShal thus indicating that the second (or third) IS-element mobilized genomic fabI copy generally appears to be a resistant allele.

\section{DISCUSSION}

A novel mobile chromosomal element based upon IS1272 and containing the sh-fabI gene of S. haemolyticus has been identified in a large-scale screen for biocide resistance across more than 1600 S. aureus isolates (Ciusa et al., 2012). This element, now named TnShal, had been found to be present in one third of triclosan resistant strains of $S$. aureus while the other triclosan resistant strains of that study had mutations either within or upstream of the enoyl-acyl carrier protein reductase fabI gene of the core genome (Ciusa et al., 2012; Grandgirard et al., 2015). A more detailed analysis of these $S$. aureus strains, and of other available staphylococcal genomes, has shown that the situation is actually more complex. The main finding of this was that sh-fabI appears to be transferred by two types of elements; TnSha1, which has a single IS1272 element, and the composite TnSha1-carrying plasmid TnSha2 which can also integrate into chromosomal IS1272 copies generating in most cases an IS1272 bordered island (Figures 1, 7). Similar congruent formations where reported for other similar elements as for example IS257 mobilizing the trimethoprim resistance determinant $d f r A$ (Leelaporn et al., 1996). As the two elements do not show any obvious species specific characteristics it was somewhat unexpected to observe such a strong divergence in distribution for these elements, with S. aureus almost exclusively harboring TnSha1, S. haemolyticus prevalently harboring TnSha2, and only S. epidermidis which was found to commonly carry both elements. Neither the GC content (TnSha1 is $31.4 \%$, TnSha 2 is $31.8 \%$, S. aureus, $S$. haemolyticus 33\%, and S. epidermidis 32\%), nor the presence of restriction modification systems nor the origin of the isolates can explain this observation; however we admit that this is as yet based on $4127 \mathrm{~S}$. aureus genomes, but upon just $286 \mathrm{~S}$. epidermidis and $141 \mathrm{~S}$. haemolyticus genomes. Similar dynamics are seen with trimethoprim resistance were the housekeeping $d f r A$ gene was acquired from other species and successfully transferred by IS257 across different staphylococcal species (Dale et al., 1995; Leelaporn et al., 1996). Whilst not explaining this difference as such, the observation that the intact IS1272 elements are present in most $S$. haemolyticus isolates, only in a few $S$. epidermidis strains and not at all in S. aureus already indicates a species specific "behavior" of the IS element. Future experiments on the transposition of the elements in the three species, will hopefully be more successful than the attempted detection of circular intermediates in S. aureus and therefore shed light on the observed differences in the epidemiology of the elements.

The mechanism of TnSha1 and IS1272 target recognition and integration appears to be novel. Both TnShal and IS1272 are seen to target hairpin secondary structures with little primary sequence conservation. In addition this insertion into the target appears to produce a blunt-end cut leading to insertion of the element and deletion of part of the target (Figures 1-4). This is in line with the original description of IS1272 which reported that the IS did not produce target duplications (Archer et al., 1996). Interestingly the recent review on IS elements by Siguier and colleagues reports that some members of the IS1182 family, of which IS1272 is part, also target palindromic sequences (Siguier et al., 2015).

Albeit that no primary sequence consensus was detected, the hairpin structures targeted by TnShal must have some important features in common as we found three targets with evidence for multiple independent insertions i.e., the targets " $\mathrm{A}$ " and " $\mathrm{X}$ " or the target " $Z$ " where we also observed multiple insertions in both orientations (Figure 2C). The absence of insertion into rolling circle replicating plasmids, coupled to the observation of insertions in opposite directions appear to indicate the absence of an orientation bias observed for IS elements inserting into the replication fork (Siguier et al., 2014). In the case of TnSha2 the situation appears to be more varied. The few available data show that TnSha2 can integrate like IS1272. In addition the few and incomplete genomic data we have could indicate that TnSha2 could be mobilized by the hypothetical ORFs present leading to duplications and co-integrate formation (Needham et al., 1995). The capacity to utilize different integration mechanisms has been described also for other transposons like Tn7 (Siguier et al., 2014).

The large number of both TnSha1 and TnSha2 element sequences available in the database has allowed us to investigate the genesis of this recently generated and spreading element. This was hampered in part by the fact that both elements included IS1272 and that these ISs, like most other repeat sequences, tend to generate contig breaks during the assembly of bacterial genomes. Given the absolute conservation of the position of IS1272 in all of the TnShal and TnSha2 elements, we favor the hypothesis that the initial steps leading to the formation of these mobile elements were very few or possibly even only a single event. The initial events in the assembly of the element 
TABLE 6 | Sh-fabl nucleotide sequence of 89 TnSha1 and TnSha2 elements.

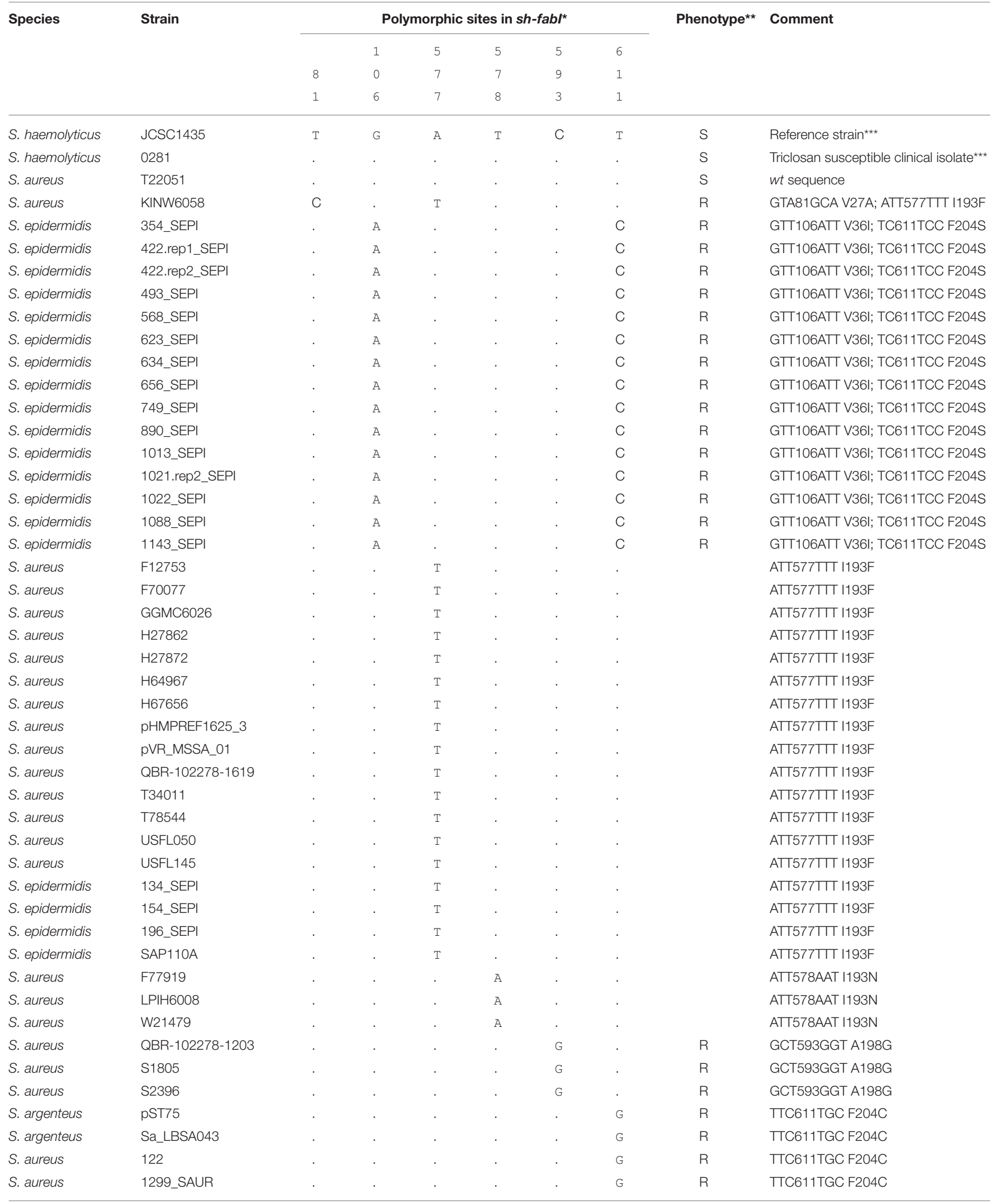

(Continued) 
TABLE 6 | Continued

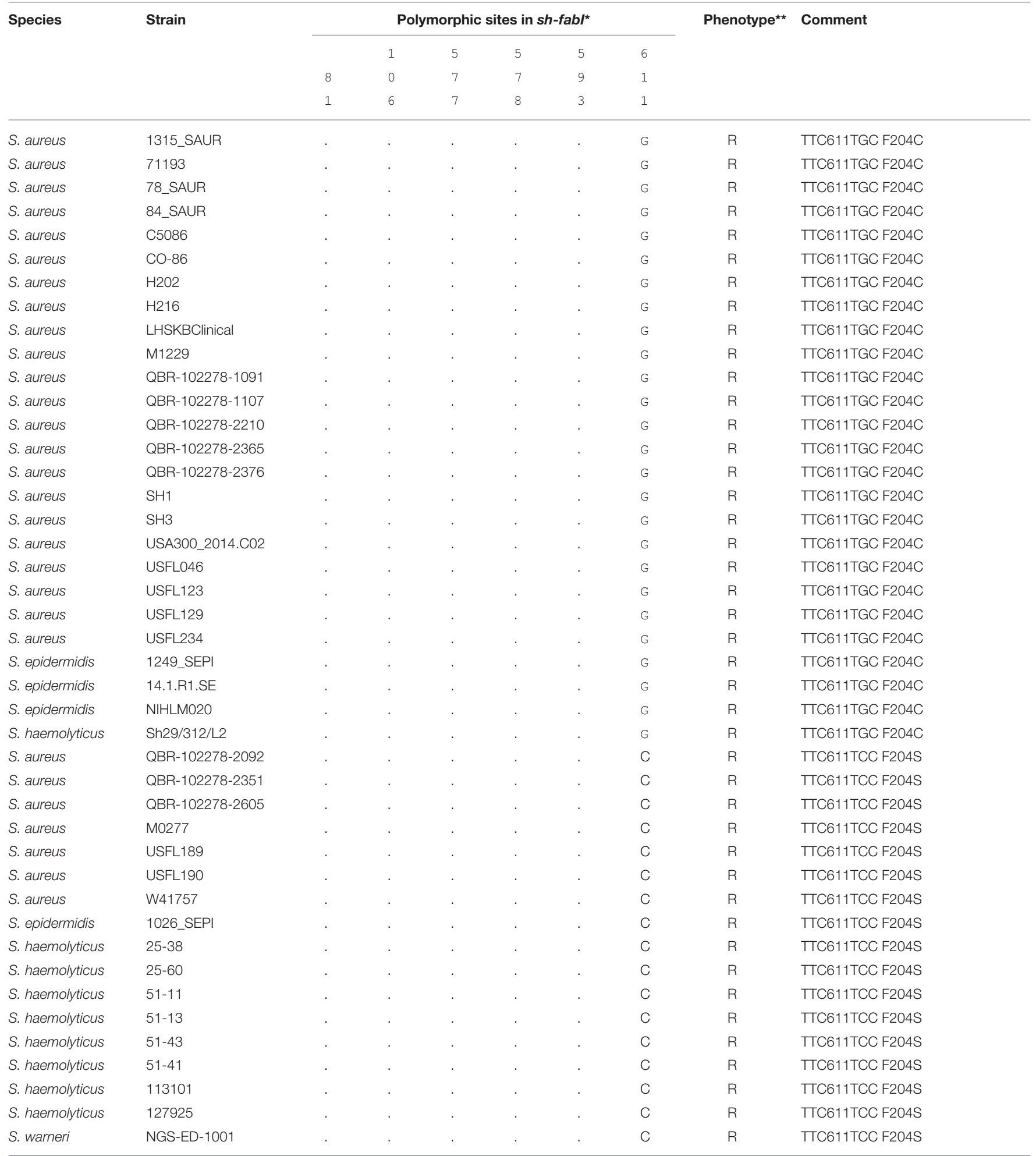

${ }^{*}$ Polymorphic sites are indicated with respect to the sh-fabl sequence of S. haemolyticus strain JCSC1435. **Phenotype as defined in references: (Ciusa et al., 2012; Grandgirard et al.,

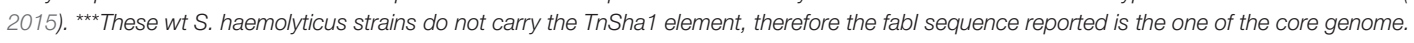


must presumably have happened in S. haemolyticus since the sh-fabI derives from the core genome of this species and both elements are also present in this species. It is again not easy to hypothesize any rationale for the almost exclusive presence of TnShal in $S$. aureus, nor for the preferential presence of TnSha2 in S. haemolyticus. The lack of primary target sequence specificity and the peculiarity of targeting hairpin secondary structures make the elements very versatile and would allow for transposition to many locations within the chromosome and on plasmids. While intact IS1272 itself is not present in S. aureus the apparent selection for TnShal has very efficiently allowed spread of the element in this species. In the case of TnSha 2 the presence of mobilization genes could indicate that this plasmid may be horizontally transferable. Unfortunately, as in the case of the $d f r$ genes (Dale et al., 1995; Leelaporn et al., 1996), none of these data provide a solid molecular basis to explain the difference in distribution of the two elements among staphylococcal species. The explanation may however come from a closer look at the structure of the elements themselves. Indeed the very limited range of the diversity in the elements, and the SNPs present in them, indicates they have a recent origin. Another important aspect of the dynamics of spread of this element is related to the different triclosan-resistance conferring SNPs which have accumulated in sh-fabI. The presence of triclosan susceptible and resistant alleles in the studied population suggests the first event was acquisition of a susceptible $s h-f a b I$ allele followed by the selection of resistant alleles after the transfer event by a fabI targeting agent, most probably triclosan (Ciusa et al., 2012; Oggioni et al., 2012, 2013; Morrissey et al., 2014; Grandgirard et al., 2015). This sequence of events in which the acquisition of a resistance element is followed by the selection of more efficient alleles is also the basis of the diversification of other resistance elements as plasmids-encoded beta-lactamases (Bush, 2013).

Type II fatty acid metabolism, and in particular FabI, are among the most highly investigated targets for development of antimicrobial compounds (Banerjee et al., 1994; Park et al., 2007; Escaich et al., 2011; Kaplan et al., 2012). This remains true even though there is now debate on the essentiality of bacterial fatty metabolism during invasive infection because, at least for group B streptococci, it has been reported that it is possible to forage host derived fatty acids (Brinster et al., 2009; Balemans et al., 2010). In this respect it is therefore of great interest to monitor the spread of genetic elements which could produce reduced susceptibility to new antibiotics whose action is based on targeting and inhibition of FabI. In this regard it is worth noting that our experimental screening of a collection of 1602 world-wide clinical S. aureus isolates detected sh-fabI in 24/1602 of strains (1.5\%; Ciusa et al., 2012), which matched perfectly with the in silico screen of a database of microbial genomes that detected sh-fabI carrying elements in 65/4127 S. aureus strains (1.57\%). This exact overlap in prevalence indicates that genome databases of such size can now serve as suitable datasets for epidemiological investigation, even though databases generally lack detailed background information on strains. While $1.5 \%$ may not appear to be a high background resistance level in a population, it could still be a worrying presence when introducing a new FabI-targeting agent. Even worse is the detection of sh-fabI elements in $14 \%$ of S. epidermidis isolates; this appears to reach levels at which clinical use, including the use of triclosan as disinfectant for decontamination, could be jeopardized. It remains possible however that the lower sample size, of $<300$ genomes screened, and the absence of clinical information on these strains may limit the relevance of this observation.

In order to correlate our data with two well-known examples of IS-mobilizable metabolic genes, we have checked the relative occurrence of the $d f r A$-thyE genes (Rouch et al., 1989), conferring trimethoprim resistance, and ileS2 genes (Needham et al., 1994), conferring mupirocin resistance, in the same 4800 staphylococcal genomes. BLAST searches for $d f r A$-thyE yielded 279 hits in $S$. aureus and 134 in S. epidermidis, while ileS2 yielded 207 hits in $S$. aureus and 18 in S. epidermidis. This compares well with the detection rate in our work of 65 TnShal/2 elements in $S$. aureus and 50 in $S$. epidermidis. These numbers indicate that IS mediated transfer of metabolic resistance genes, in our case sh-fabI genes and triclosan resistance, is a highly relevant mechanism for the acquisition and spread of antibiotic resistance. These data show that it is not only plasmids which serve as vectors of IS mediated resistance gene transfers, but that the spread of composite transposons can also be a highly efficient mechanism for such a goal. A similar well-described mechanisms also exist in staphylococci for the antibiotic resistance genes for example in Tn4001, Tn4002, and Tn4003, (Lanza et al., 2015).

In conclusion our data show that IS mediated transposition of metabolic genes represents a vast and growing antimicrobial resistance phenomenon. In addition to the well-described Tn4003 element, which mobilizes $d f r A$ by way of three IS257 thereby conferring trimethoprim resistance (Rouch et al., 1989), or the IS257 mediated mobilization of ileS2 conferring mupirocin resistance (Needham et al., 1995), this arsenal now includes TnSha1 and TnSha2; these elements utilize IS transposition, IS-targeted integration and plasmid mobilization to allow transfer of the fabI gene of S. haemolyticus to different staphylococci and thereby contribute to triclosan resistance and, potentially, to resistance for other FabI-targeting drugs. These data show that IS mobilization of metabolic genes is a powerful and highly flexible mechanism that can very rapidly provide resistance phenotypes to vast numbers of strains and species. In this era where thousands of genomes are readily available in public databases the analysis of such IS mediated mobilization of core genome metabolic genes may warrant a more detailed and larger scale investigation.

\section{AUTHOR CONTRIBUTIONS}

LF performed the genome sequencing and bioinformatic analysis, wrote the manuscript, and approved the final version. $\mathrm{RH}$ participated in bioinformatic analysis, wrote the manuscript, and approved the final version. ZA performed wet lab experiments, participated in bioinformatic analysis, participated in the revision of the manuscript, and approved the final version. HO preformed bioinformatic analysis, discussed results and implication and helped in revision of the manuscript 
and approved the final version. IM had input in the initial study design, participated in the generation and analysis of data, the revision of the manuscript, and approved the final version. RL preformed bioinformatic analysis, discussed results and implication and helped in revision of the manuscript and approved the final version. JM had input in the initial study design, participated in the analysis of data, participated in the revision of the manuscript, and approved the final version. TC had input in the initial study design, participated in the analysis of data, participated in the revision of the manuscript, and approved the final version. MO designed the study, participated in bioinformatic analysis, wrote the manuscript, and is accountable for all aspects of the work.

\section{REFERENCES}

Altschul, S. F., Madden, T. L., Schaffer, A. A., Zhang, J., Zhang, Z., Miller, W., et al. (1997). Gapped BLAST and PSI-BLAST: a new generation of protein database search programs. Nucleic Acids Res. 25, 3389-3402. doi: 10.1093/nar/25.17.3389

Andersson, D. I. (2006). The biological cost of mutational antibiotic resistance: any practical conclusions? Curr. Opin. Microbiol. 9, 461-465. doi: 10.1016/j.mib.2006.07.002

Archer, G. L., Niemeyer, D. M., Thanassi, J. A., and Pucci, M. J. (1994). Dissemination among staphylococci of DNA sequences associated with methicillin resistance. Antimicrob. Agents Chemother. 38, 447-454. doi: 10.1128/AAC.38.3.447

Archer, G. L., Thanassi, J. A., Niemeyer, D. M., and Pucci, M. J. (1996). Characterization of IS1272, an insertion sequence-like element from Staphylococcus haemolyticus. Antimicrob. Agents Chemother. 40, 924-929.

Balemans, W., Lounis, N., Gilissen, R., Guillemont, J., Simmen, K., Andries, K., et al. (2010). Essentiality of FASII pathway for Staphylococcus aureus. Nature 463, E3. discussion: E4. doi: 10.1038/nature08667

Banerjee, A., Dubnau, E., Quemard, A., Balasubramanian, V., Um, K. S., Wilson, T., et al. (1994). inhA, a gene encoding a target for isoniazid and ethionamide in Mycobacterium tuberculosis. Science 263, 227-230.

Barth, P. T., Datta, N., Hedges, R. W., and Grinter, N. J. (1976). Transposition of a deoxyribonucleic acid sequence encoding trimethoprim and streptomycin resistances from R483 to other replicons. J. Bacteriol. 125, 800-810.

Bosi, E., Donati, B., Galardini, M., Brunetti, S., Sagot, M. F., Lio, P., et al. (2015). MeDuSa: a multi-draft based scaffolder. Bioinformatics 31, 2443-2451. doi: 10.1093/bioinformatics/btv171

Brinster, S., Lamberet, G., Staels, B., Trieu-Cuot, P., Gruss, A., and Poyart, C. (2009). Type II fatty acid synthesis is not a suitable antibiotic target for Gram-positive pathogens. Nature 458, 83-86. doi: 10.1038/nature07772

Bush, K. (2013). Proliferation and significance of clinically relevant betalactamases. Ann. N.Y. Acad. Sci. 1277, 84-90. doi: 10.1111/nyas.12023

Cavanagh, J. P., Hjerde, E., Holden, M. T., Kahlke, T., Klingenberg, C., Flaegstad, T., et al. (2014). Whole-genome sequencing reveals clonal expansion of multiresistant Staphylococcus haemolyticus in European hospitals. J. Antimicrob. Chemother. 69, 2920-2927. doi: 10.1093/jac/dku271

Ciusa, M. L., Furi, L., Knight, D., Decorosi, F., Fondi, M., Raggi, C., et al. (2012). A novel resistance mechanism to triclosan that suggests horizontal gene transfer and demonstrates a potential selective pressure for reduced biocide susceptibility in clinical strains of Staphylococcus aureus. Int. J. Antimicrob. Agents 40, 210-220. doi: 10.1016/j.ijantimicag.2012.04.021

Coelho, J. R., Carrico, J. A., Knight, D., Martinez, J. L., Morrissey, I., Oggioni, M. R., et al. (2013). The use of machine learning methodologies to analyse antibiotic and biocide susceptibility in Staphylococcus aureus. PLoS ONE 8:e55582. doi: 10.1371/journal.pone.0055582

Dale, G. E., Broger, C., Hartman, P. G., Langen, H., Page, M. G., Then, R. L., et al. (1995). Characterization of the gene for the chromosomal dihydrofolate reductase (DHFR) of Staphylococcus epidermidis ATCC 14990: the origin of the

\section{FUNDING}

The work was in part supported by EC project KBBE-227258 (BIOHYPO). ZA is funded by a fellowship of the Sultan Qaboos University, Oman.

\section{ACKNOWLEDGMENTS}

We thank Mike Chandler for helpful discussion. In addition to the authors, Graziella Orefici, Carlo Viti, Ulku Yetis, Hans Joachim Roedger, Ayse Kalkancy, Pilar Visa, Marina Elli, Stephen Leib, Daniel Knight and Diego Mora, participated to the BIOHYPO research project.

trimethoprim-resistant S1 DHFR from Staphylococcus aureus? J. Bacteriol. 177, 2965-2970.

Deeny, S. R., Worby, C. J., Tosas Auguet, O., Cooper, B. S., Edgeworth, J., Cookson, B., et al. (2015). Impact of mupirocin resistance on the transmission and control of healthcare-associated MRSA. J. Antimicrob. Chemother. 70, 3366-3378. doi: $10.1093 / \mathrm{jac} / \mathrm{dkv} 249$

Escaich, S., Prouvensier, L., Saccomani, M., Durant, L., Oxoby, M., Gerusz, V., et al. (2011). The MUT056399 inhibitor of FabI is a new antistaphylococcal compound. Antimicrob. Agents Chemother. 55, 4692-4697. doi: 10.1128/AAC.01248-10

Fagerlund, A., Granum, P. E., and Havarstein, L. S. (2014). Staphylococcus aureus competence genes: mapping of the SigH, ComK1 and ComK2 regulons by transcriptome sequencing. Mol. Microbiol. 94, 557-579. doi: 10.1111/mmi. 12767

Furi, L., Ciusa, M. L., Knight, D., Di Lorenzo, V., Tocci, N., Cirasola, D., et al. (2013). Evaluation of reduced susceptibility to quaternary ammonium compounds and bisbiguanides in clinical isolates and laboratory-generated mutants of Staphylococcus aureus. Antimicrob. Agents Chemother. 57, 3488-3497. doi: 10.1128/AAC.00498-13

Gilbart, J., Perry, C. R., and Slocombe, B. (1993). High-level mupirocin resistance in Staphylococcus aureus: evidence for two distinct isoleucyl-tRNA synthetases. Antimicrob. Agents Chemother. 37, 32-38. doi: 10.1128/AAC.37.1.32

Grandgirard, D., Furi, L., Ciusa, M. L., Baldassarri, L., Knight, D. R., Morrissey, I., et al. (2015). Mutations upstream of fabI in triclosan resistant Staphylococcus aureus strains are associated with elevated fabI gene expression. BMC Genomics 16:345 doi: 10.1186/s12864-015-1544-y

Heath, R. J., Rubin, J. R., Holland, D. R., Zhang, E., Snow, M. E., and Rock, C. O. (1999). Mechanism of triclosan inhibition of bacterial fatty acid synthesis. J. Biol. Chem. 274, 11110-11114. doi: 10.1074/jbc.274.16.11110

Heath, R. J., White, S. W., and Rock, C. O. (2001). Lipid biosynthesis as a target for antibacterial agents. Prog. Lipid Res. 40, 467-497. doi: 10.1016/S01637827(01)00012-1

Hedges, R. W., and Jacob, A. E. (1974). Transposition of ampicillin resistance from RP4 to other replicons. Mol. Gen. Genet. 132, 31-40. doi: 10.1007/BF00268228

Hetem, D. J., and Bonten, M. J. (2013). Clinical relevance of mupirocin resistance in Staphylococcus aureus. J. Hosp. Infect. 85, 249-256. doi: 10.1016/j.jhin.2013.09.006

Hijazi, K., Mukhopadhya, I., Abbott, F., Milne, K., Al-Jabri, Z. J., Oggioni, M. R., et al. (2016). Susceptibility to chlorhexidine amongst multidrug-resistant clinical isolates of Staphylococcus Epidermidis from bloodstream infections. Int. J. Antimicrob. Agents. doi: 10.1016/j.ijantimicag.2016.04.015. [Epub ahead of print].

Isola, D., Pardini, M., Varaine, F., Niemann, S., Rusch-Gerdes, S., Fattorini, L., et al. (2005). A pyrosequencing assay for rapid recognition of SNPs in Mycobacterium tuberculosis embB306 region. J. Microbiol. Methods 62, 113-120. doi: 10.1016/j.mimet.2005.02.004

Ji, Y., Yin, D., Fox, B., Holmes, D. J., Payne, D., and Rosenberg, M. (2004) Validation of antibacterial mechanism of action using regulated antisense RNA 
expression in Staphylococcus aureus. FEMS Microbiol. Lett. 231, 177-184. doi: 10.1016/S0378-1097(03)00931-5

Kaplan, N., Albert, M., Awrey, D., Bardouniotis, E., Berman, J., Clarke, T., et al. (2012). Mode of action, in vitro activity, and in vivo efficacy of AFN-1252, a selective antistaphylococcal FabI inhibitor. Antimicrob. Agents Chemother. 56, 5865-5874. doi: 10.1128/AAC.01411-12

Lanza, V. F., Tedim, A. P., Martinez, J. L., Baquero, F., and Coque, T. M. (2015). The plasmidome of firmicutes: impact on the emergence and the spread of resistance to antimicrobials. Microbiol. Spectr. 3:PLAS-0039-2014. doi: 10.1128/microbiolspec.plas-0039-2014

Larsen, M. V., Cosentino, S., Rasmussen, S., Friis, C., Hasman, H., Marvig, R. L., et al. (2012). Multilocus sequence typing of total-genome-sequenced bacteria. J. Clin. Microbiol. 50, 1355-1361. doi: 10.1128/JCM.06094-11

Leelaporn, A., Firth, N., Paulsen, I. T., and Skurray, R. A. (1996). IS257-mediated cointegration in the evolution of a family of staphylococcal trimethoprim resistance plasmids. J. Bacteriol. 178, 6070-6073.

León-Sampedro, R., Novais, C., Peixe, L., Baquero, F., and Coque, T. M. (2016). Diversity and evolution of the Tn5801-tet(M)-like integrative and conjugative elements among Enterococcus, Streptococcus, and Staphylococcus. Antimicrob. Agents Chemother. 60, 1736-1746. doi: 10.1128/AAC.01864-15

Li, H. (2014). Toward better understanding of artifacts in variant calling from high-coverage samples. Bioinformatics 30, 2843-2851. doi: 10.1093/bioinformatics/btu356

Lu, H., and Tonge, P. J. (2008). Inhibitors of FabI, an enzyme drug target in the bacterial fatty acid biosynthesis pathway. Acc. Chem. Res. 41, 11-20. doi: 10.1021/ar700156e

Maillard, J. Y., Bloomfield, S., Coelho, J. R., Collier, P., Cookson, B., Fanning, S., et al. (2013). Does microbicide use in consumer products promote antimicrobial resistance? a critical review and recommendations for a cohesive approach to risk assessment. Microb. Drug Resist. 19, 344-354. doi: $10.1089 / \mathrm{mdr} .2013 .0039$

Martinez, J. L., Coque, T. M., and Baquero, F. (2015). What is a resistance gene? Ranking risk in resistomes. Nat. Rev. Microbiol. 13, 116-123. doi: 10.1038/nrmicro3399

Morrissey, I., Oggioni, M. R., Knight, D., Curiao, T., Coque, T., Kalkanci, A., et al. (2014). Evaluation of epidemiological cut-off values indicates that biocide resistant subpopulations are uncommon in natural isolates of clinically-relevant microorganisms. PLOS ONE 9:e86669. doi: 10.1371/journal.pone.0086669

Needham, C., Noble, W. C., and Dyke, K. G. (1995). The staphylococcal insertion sequence IS257 is active. Plasmid 34, 198-205. doi: 10.1006/plas.1995.0005

Needham, C., Rahman, M., Dyke, K. G., and Noble, W. C. (1994). An investigation of plasmids from Staphylococcus aureus that mediate resistance to mupirocin and tetracycline. Microbiology 140 (Pt 10), 2577-2583. doi: 10.1099/00221287140-10-2577

Oggioni, M. R., Ciusa, M. L., Furi, L., Baldassarri, L., Orefici, G., Cirasola, D., et al. (2012). Lack of evidence for reduced fitness of clinical Staphylococcus aureus isolates with reduced susceptibility to triclosan. Antimicrob. Agents Chemother. 56, 6068-6069. doi: 10.1128/AAC.01055-12

Oggioni, M. R., Coelho, J. R., Furi, L., Knight, D. R., Viti, C., Orefici, G., et al. (2015). Significant differences characterise the correlation coefficients between biocide and antibiotic susceptibility profiles in Staphylococcus aureus. Curr. Pharm. Des. 21, 2054-2057. doi: 10.2174/1381612821666150310103238

Oggioni, M. R., Furi, L., Coelho, J. R., Maillard, J. Y., and Martinez, J. L. (2013). Recent advances in the potential interconnection between antimicrobial resistance to biocides and antibiotics. Expert Rev. Anti Infect. Ther. 11, 363-366. doi: 10.1586/eri.13.16

Oggioni, M. R., Meacci, F., Carattoli, A., Ciervo, A., Orru, G., Cassone, A., et al. (2002). Protocol for real-time PCR identification of anthrax spores from nasal swabs after broth enrichment. J. Clin. Microbiol. 40, 3956-3963. doi: 10.1128/JCM.40.11.3956-3963.2002

Park, H. S., Yoon, Y. M., Jung, S. J., Kim, C. M., Kim, J. M., and Kwak, J. H. (2007). Antistaphylococcal activities of CG400549, a new bacterial enoyl-acyl carrier protein reductase (FabI) inhibitor. J. Antimicrob. Chemother. 60, 568-574. doi: $10.1093 / \mathrm{jac} / \mathrm{dkm} 236$
Payne, D. J., Warren, P. V., Holmes, D. J., Ji. Y., and Lonsdale, J. T. (2001) Bacterial fatty-acid biosynthesis: a genomics-driven target for antibacterial drug discovery. Drug Discov. Today 6, 537-544. doi: 10.1016/S1359-6446(01) 01774-3

Reuter, J. S., and Mathews, D. H. (2010). RNAstructure: software for RNA secondary structure prediction and analysis. BMC Bioinformatics 11:129. doi: 10.1186/1471-2105-11-129

Roach, D. J., Burton, J. N., Lee, C., Stackhouse, B., Butler-Wu, S. M., Cookson, B. T., et al. (2015). A year of infection in the intensive care unit: prospective whole genome sequencing of bacterial clinical isolates reveals cryptic transmissions and novel microbiota. PLoS Genet. 11:e1005413. doi: 10.1371/journal.pgen.1005413

Rouch, D. A., Messerotti, L. J., Loo, L. S., Jackson, C. A., and Skurray, R. A. (1989). Trimethoprim resistance transposon Tn4003 from Staphylococcus aureus encodes genes for a dihydrofolate reductase and thymidylate synthetase flanked by three copies of IS257. Mol. Microbiol. 3, 161-175. doi: 10.1111/j.13652958.1989.tb01805.x

Schoenfelder, S. M., Lange, C., Eckart, M., Hennig, S., Kozytska, S., and Ziebuhr, W. (2010). Success through diversity - how Staphylococcus epidermidis establishes as a nosocomial pathogen. Int. J. Med. Microbiol. 300, 380-386. doi: 10.1016/j.ijmm.2010.04.011

Schweizer, H. P. (2001). Triclosan: a widely used biocide and its link to antibiotics. FEMS Microbiol. Lett. 202, 1-7. doi: 10.1111/j.1574-6968.2001. tb10772.x

Siguier, P., Gourbeyre, E., and Chandler, M. (2014). Bacterial insertion sequences: their genomic impact and diversity. FEMS Microbiol. Rev. 38, 865-891. doi: $10.1111 / 1574-6976.12067$

Siguier, P., Gourbeyre, E., Varani, A., Ton-Hoang, B., and Chandler, M. (2015). Everyman's guide to bacterial insertion sequences. Microbiol. Spectr. 3:MDNA3-0030-2014 doi: 10.1128/microbiolspec.mdna3-00302014

Slater-Radosti, C., Van Aller, G., Greenwood, R., Nicholas, R., Keller, P. M. DeWolf, W. E. Jr., et al. (2001). Biochemical and genetic characterization of the action of triclosan on Staphylococcus aureus. J. Antimicrob. Chemother. 48 1-6. doi: 10.1093/jac/48.1.1

Tonouchi, N., Tsuchida, T., Yoshinaga, F., Horinouchi, S., and Beppu, T. (1994). A host-vector system for a cellulose-producing Acetobacter strain. Biosci. Biotechnol. Biochem. 58, 1899-1901. doi: 10.1271/bbb. 58.1899

Woodford, N., Watson, A. P., Patel, S., Jevon, M., Waghorn, D. J., and Cookson, B. D. (1998). Heterogeneous location of the mupA high-level mupirocin resistance gene in Staphylococcus aureus. J. Med. Microbiol. 47, 829-835. doi: 10.1099/00222615-47-9-829

Yesilkaya, H., Meacci, F., Niemann, S., Hillemann, D., Rusch-Gerdes, S., Group, L. D. S., et al. (2006). Evaluation of molecular-Beacon, TaqMan, and fluorescence resonance energy transfer probes for detection of antibiotic resistance-conferring single nucleotide polymorphisms in mixed Mycobacterium tuberculosis DNA extracts. J. Clin. Microbiol. 44, 3826-3829. doi: 10.1128/JCM.00225-06

Zhang, Y. Q., Ren, S. X., Li, H. L., Wang, Y. X., Fu, G., Yang, J., et al. (2003). Genome-based analysis of virulence genes in a non-biofilmforming Staphylococcus epidermidis strain (ATCC 12228). Mol. Microbiol. 49, 1577-1593. doi: 10.1046/j.1365-2958.2003.03671.x

Conflict of Interest Statement: The authors declare that the research was conducted in the absence of any commercial or financial relationships that could be construed as a potential conflict of interest.

Copyright (c) 2016 Furi, Haigh, Al Jabri, Morrissey, Ou, León-Sampedro, Martinez, Coque and Oggioni. This is an open-access article distributed under the terms of the Creative Commons Attribution License (CC BY). The use, distribution or reproduction in other forums is permitted, provided the original author(s) or licensor are credited and that the original publication in this journal is cited, in accordance with accepted academic practice. No use, distribution or reproduction is permitted which does not comply with these terms. 